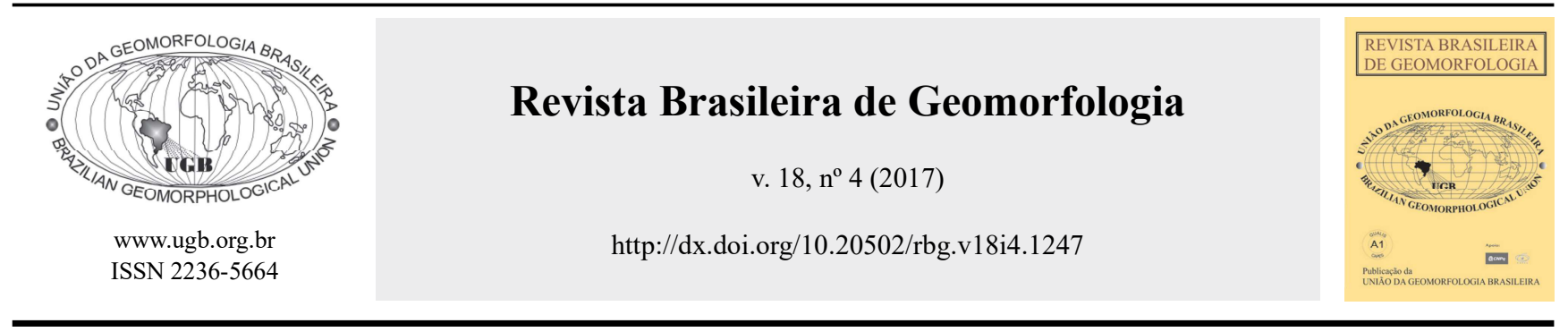

\title{
DINÂMICA DE RAMPA DE COLÚVIO NA SUPERFÍCIE DE PALMAS/ÁGUA DOCE DURANTE O QUATERNÁRIO TARDIO - BASES PARA COMPREENDER A EVOLUÇÃO DAS ENCOSTAS NO PLANALTO DAS ARAUCÁRIAS
}

\author{
DYNAMICS OF COLLUVIUM RAMP ON THE SURFACE OF PALMAS/ÁGUA \\ DOCE DURING THE LATE QUATERNARY - BASES TO UNDERSTAND THE \\ EVOLUTION SLOPES IN THE ARAUCARIAS PLATEAU
}

\author{
Julio Cesar Paisani \\ Departamento de Geografia, Universidade Estadual do Oeste do Paraná \\ Rua Maringá 1.200, Francisco Beltrão, Paraná. CEP 85.605.010. Brasil \\ Email:juliopaisani@hotmail.com \\ Sani Daniela Lopes Paisani \\ Departamento de Geografia, Universidade Estadual do Oeste do Paraná \\ Rua Maringá 1.200, Francisco Beltrão, Paraná. CEP 85.605.010. Brasil \\ Email: sanidaniela@hotmail.com
}

Margarita Luisa Osterrieth Instituto de Geologia de Costas y del Cuaternario, Universidad Nacional de Mar del Plata C. C. 722. Funes 3350, Mar del Plata, Cx Postal 772. CEP: 7600. Argentina Email:mosterri@hotmail.com

Marga Eliz Pontelli Departamento de Geografia, Universidade Estadual do Oeste do Paraná Rua Maringá 1.200, Francisco Beltrão, Paraná. CEP 85.605.010. Brasil Email:mepontelli@hotmail.com

Rafaela Harumi Fujita Departamento de Geografia, Universidade Estadual do Oeste do Paraná Rua Maringá 1.200, Francisco Beltrão, Paraná. CEP 85.605.010. Brasil Email:rfharumi@yahoo.com.br

\section{Informações sobre o Artigo}

Recebido (Received):

25/03/2017

Aceito (Accepted):

$31 / 07 / 2017$

Palavras-chave:

Encosta; Paleofundo de Vale; Fitólito; Isótopo do Carbono.

\section{Resumo:}

O termo rampa de colúvio consiste em unidade de relevo suavemente inclinada em direção ao fundo dos vales mantida por colúvios, por vezes recobrindo terraços aluviais e reentrâncias (hollows) ou depressões em anfiteatro. O presente trabalho visou determinar a dinâmica de rampa de colúvio da superfície de Palmas/Água Doce, ao longo do Quaternário Tardio, bem como tecer considerações a respeito do ambiente de encostas em superfícies de cimeira do Planalto das Araucárias, sul do Brasil. Aplicou-se a análise pedoestratigráfica em duas seções representativas dos materiais de rampa de colúvio, bem como a geocronologia (métodos ${ }^{14} \mathrm{C}$ e LOE) 
Keywords:

Slope; Valley Paleobottom; Phytolith; Carbon Isotope.

e análises isotópica do carbono e fitolítica. A rampa de colúvio relevou registro pedoestratigráfico caracterizado por camadas delgadas de colúvios (horizontes $\mathrm{Cb}$ ), por vezes pedogenizadas (horizontes $\mathrm{Ab}, \mathrm{ACb}, \mathrm{CAb}, \mathrm{Bb}$ e $\mathrm{BCb}$ ), com importantes lacunas e truncamentos de níveis pedológicos superficiais (paleohorizontes A). Vales de drenagem de baixa ordem vizinhos às encostas sofreram colmatação durante sucessivas fases de sedimentação. A morfogênese foi contínua no setor analisado do Último Interglacial (Estágio Isotópico Marinho 3 - EIM 3 ) ao Holoceno (EIM 1). Os sinais isotópicos e fitolíticos sugerem que a estabilidade ambiental favorecendo a pedogênese no Último Interestadial (EIM 3) e foi em detrimento de regime climático úmido e relativamente frio. Já a morfogênese registrada no Último Máximo Glacial (EIM 2) decorreu de regime climático relativamente frio e seco, pontuada por fase de flutuação para mais úmido. Enfim, para o Holoceno (EIM 1) o clima mostrou-se no geral mais quente e seco. Do ponto de vista regional, os resultados indicam que: a) as rampas de colúvio são unidades geomórficas de trânsito de sedimentos entre colinas e fundo de vale de baixa ordem nas superfícies de cimeira do Planalto das Araucárias; b) seus registros estratigráficos são delgados em face a recorrentes lacunas (descontinuidades); c) a intensa dinâmica erosiva nas rampas inibe o acúmulo de sedimentos, por outro lado possibilita a colmatação de fundos de vales de baixa ordem vizinhos, até completa homogeneização topográfica lateral; d) nesses fundos de vales estão os principais registros estratigráficos que documentam fases de pedogênese e morfogênese tanto no ambiente de encosta quanto no ambiente fluvial de baixa ordem vinculado a rampa; e) paleohorizontes A húmicos enterrados (Ab), vinculados a fase de pedogênese do Último Máximo Glacial, podem estar preservados em ambos os ambientes.

\begin{abstract}
:
The term colluvium ramp consists of a gently sloping relief unit towards the bottom of the valleys maintained by colluvium, sometimes covering alluvial terraces and hollows or depressions in amphitheater. The present work aimed to determine the dynamics of the colluvium ramp of the Palmas / Água Doce surface along the Late Quaternary, as well as to make considerations about the slope environment on the summit surfaces of the Araucarias Plateau, southern Brazil. The pedostratigraphic analysis was applied in two representative sections of the colluvio ramp materials, as well as the geochronology (14C and LOE methods), carbon isotopic and phytolith analysis. The colluvium ramp revealed a pedostratigraphic record characterized by thin layers of colluvium (horizons $\mathrm{Cb}$ ), sometimes pedogenized (horizons $\mathrm{Ab}, \mathrm{ACb}, \mathrm{CAb}, \mathrm{Bb}$ and $\mathrm{BCb}$ ), with important gaps and truncations of superficial pedological levels (paleohorizonts A). Low-order drainage valleys bordering the slopes were clogged during successive stages of sedimentation. The morphogenesis was continuous in the analyzed section of the Last Interglacial (Marine Isotopic Stage 3 - MIS 3) to the Holocene (MIS 1). Isotopic and phytolithic signals suggest that environmental stability favoring pedogenesis in the Last Interstate (MIS 3) was detrimental to a relatively cold and humid climate regime. The morphogenesis recorded in the Late Glacial Maximum (MIS 2) was due to a relatively cold and dry climatic regime, marked by a fluctuation phase and a more humid one. Anyway, for the Holocene (MIS 1) the weather was generally warmer and drier. From a regional point of view, the results indicate that: a) colluvial ramps are geomorphic sediment transit units between hills and low valley bottom in the summit surfaces of the Araucaria Plateau; B) its stratigraphic records are thin in the face of recurrent gaps (discontinuities); C) the intense erosive dynamics on the ramps inhibits the accumulation of sediments, on the other hand it allows the closure of funds from neighboring low-order valleys until complete lateral topographic homogenization; D) in these valleys bottoms are the main stratigraphic records that document phases of pedogenesis and morphogenesis both in the slope environment and in the low order fluvial environment linked to ramp; E) paleohorizonts humic A buried $(\mathrm{Ab})$, linked to the phase of last glacial maximum pedogenesis, may be preserved in both environments.
\end{abstract}

\section{Introdução}

O termo rampa de colúvio foi sugerido por Bigarella e Mousinho (1965) para expressar topografia suavemente inclinada (glacis) em direção ao fundo dos vales. Essa morfologia seria mantida por colúvios e resultaria de sucessivas fases de remobilização de mate- riais nas encostas e acumulação em seu sopé, por vezes recobrindo terraços aluviais e reentrâncias (hollows) ou depressões de relevo em anfiteatro (IBGE, 2009).

A incorporação do termo rampa de colúvio em trabalhos subsequentes de Geomorfologia do Quaternário conduziu a reflexões a respeito de sua conceituação 
(MOURA e SILVA, 2006). Delas se destaca o aspecto morfológico, em que se considera rampa de colúvio a morfologia que envolve o local de deposição de colúvios, bem como a respectiva área fonte (MEIS e MONTEIRO, 1979).

Rampas de colúvio são comuns na superfície de Palmas/Água Doce em torno de relevos residuais e encostas de fundos de vales de baixa ordem $\left(<4^{\mathrm{a}}\right.$ ordem). A dinâmica geomorfológica e paleoambiental dessa superfície vêm sendo levantada nos últimos dez anos, cujos principais eventos de pedogênese e morfogênese estão documentados em registros estratigráficos encontrados em fundos de vales de baixa ordem e cabeceiras de drenagem fossilizadas na paisagem, designados, respectivamente, de paleofundo de vales e paleocabeceiras de drenagem (PAISANI et al., 2014). Por outro lado, não se sabe se a dinâmica das rampas de colúvio nessa superfície está em fase com os referidos eventos. Diante disso, este trabalho visou determinar a dinâmica de rampa de colúvio da superfície de Palmas/ Água Doce, ao longo do Quaternário Tardio, bem como tecer considerações a respeito do ambiente de encostas em superfícies de cimeira do Planalto das Araucárias, sul do Brasil.

\section{2. Área de Estudo}

No contexto geomorfológico regional, a rampa de colúvio estudada insere-se na superfície de Palmas/ Água Doce, uma das unidades de cimeira do Planalto das Araucárias (Figura 1A). Trata-se de superfície fortemente dissecada situada nos estados do Paraná e Santa Catarina, região sul do Brasil, entre 1.200 a 1.300 m de altitude (PAISANI et al., 2008 - Figura 1A). A altitude lhe impõe regime climático, segundo classificação de Köppen, do tipo Cfa (MAACK, 1981), com precipitação média de $1.590 \mathrm{~mm}$. ano ${ }^{-1}$ bem distribuída e temperatura média anual de $15^{\circ} \mathrm{C}$ (média máxima $=26^{\circ} \mathrm{C}$ e média mínima $\left.=4^{\circ} \mathrm{C}\right)$ (PAISANI et al., 2016a).

A superfície de Palmas/Água Doce é mantida por riolitos e derrames hidrotermais derivados da Formação Serra Geral, Bacia do Paraná (CHMYZ, 2013; LIMA, 2013) (Figura 1). Seu relevo é marcado por mesetas (relevos residuais), colinas convexas (Figura 1B), e fundos de vales tanto abertos (forma $U$ ) quanto fechados (forma V). Considerando o aspecto morfográfico, bem como ausência de sedimentos típicos fácies fluviais, os fundos de vales abertos são vistos como pedimentos (BIGARELLA et al., 1965), cuja drenagem ocorre predominantemente em canais intermitentes em ambiente de brejo/várzea. Os fundos de vales fechados apresentam corredeiras, sucessivos knickpoints e canais perenes. As formações superficiais nos ambientes brejos são constituídas de solos hidromórficos, enquanto que as colinas convexas apresentam solos litólicos, ambas com horizonte A proeminente.

A rampa de colúvio estudada bordeja colina convexa que delimita a margem direita de canal de $4^{\mathrm{a}}$ ordem (Classificação de Strahler) do sistema hidrográfico do rio Chopinzinho (Figura 1A,2A). Sua morfologia é perceptível em face a cobertura vegetal rasteira constituída principalmente de gramínea que recobre toda a colina (Figura 1A). Ela corresponde a vegetação natural de Campo (MAACK, 1948 e 1949), sistematicamente regenerada por queimadas e pastoreio. O pastoreio de gado ao longo da rampa de colúvio, bem como da colina convexa, é uma atividade extensiva contínua desde o início do século vinte.

Os materiais de encosta lateralmente estão justapostos (coalescem) com materiais de leque aluvial de canal de $1^{\text {a }}$ ordem desconectado da rede de drenagem que remonta a colina convexa (Figura 1A, 2A). O leque aluvial se desenvolveu sobre sedimentos coluviais na desembocadura do canal de $1^{\mathrm{a}}$ ordem (Figura $2 \mathrm{~A}$ ), cuja morfologia convexa é pouco nítida em face da cobertura florestal moderna (FOM - Floresta Ombrófila Mista regenerada) (Figura 1A). Os materiais tanto do leque aluvial, quanto da rampa de colúvio, estão expostos em corte transversal de estrada rural (Figura 1B, C, D, 2A).

\section{Materiais e Métodos}

Os materiais da rampa de colúvio foram descritos por meio de duas seções estratigráficas estabelecidas perpendiculares a rampa em corte de estrada rural (Figura 1A). A primeira exemplifica fácies coluvial (seção Hs18), enquanto que a segunda é composta de fácies coluvial e aluvial (seção Hs12). Em ambos os registros foram encontrados sedimentos com diferentes graus de pedogênese, discordâncias verticais e descontinuidades laterais. Diante disso, foi aplicado em conjunto os critérios lito-, pedo-, alo- e cronoestratigráficos para individualizar as unidades estratigráficas (HUGHES, 2010). Na sequencia aplicou-se descrições e nomenclatura pedoestratigráfica (CATT, 1990), igualmente ao que foi feito para outras seções estratigráficas descritas na área (PAISANI et al., 2016a). 


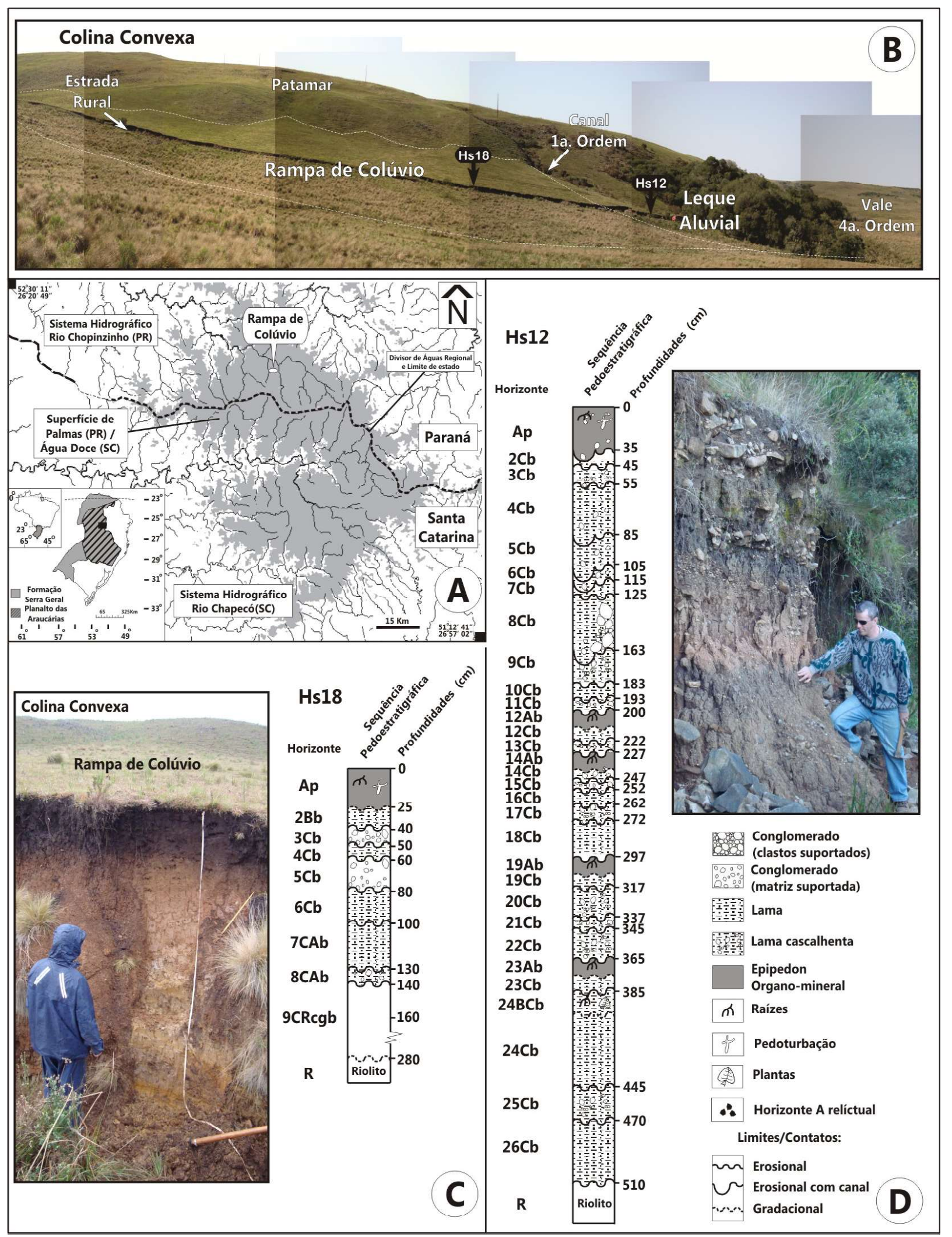

Figura 1 - Superfície de Palmas/Água Doce no contexto do Planalto das Araucárias (A). Foto da Rampa de Colúvio em vale de $4^{a}$ ordem hierárquica do sistema hidrográfico do rio Chopinzinho (B). Nota-se: a) contínuo topográfico lateral entre encosta e leque aluvial situado na desembocadura de canal de $1^{a}$ ordem desconectado da rede de drenagem; e b) locais de estabelecimento das seções Hs 18 e Hs 12 . Fotos em detalhe das seções Hs 18 e Hs 12 com respectivas seções colunares contendo a individualização de unidades pedoestratigráficas (C,D) (modificado de PAISANI et al., 2012; PAISANI, 2015;). 


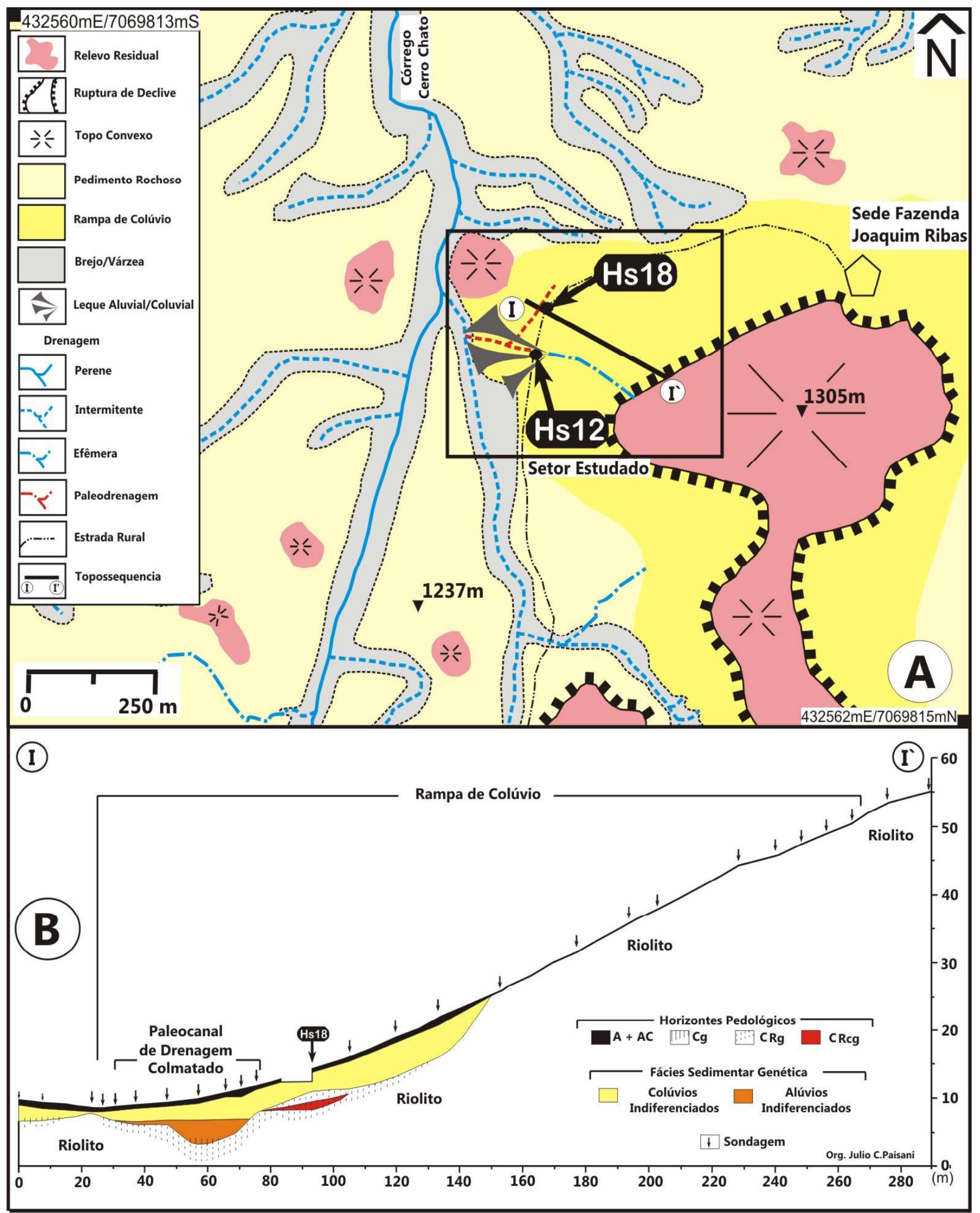

Figura 2 - Contexto geomorfológico da rampa de colúvio (A). Topossequencia longitudinal a rampa de colúvio (B). Nota-se que a mesma se estende pelos terços superior e médio da colina, os quais são os setores fonte dos materiais coluviais. 
Foi estabelecida topossequencia (distribuição bidimensional dos materiais) perpendicular a seção Hs 18, por meio de sondagens a trado holandês, baseado em Paisani e Oliveira (1998). A topossequencia foi estabelecida pelo método de caminhamento utilizando-se clinômetro, metro de madeira, trena, bússola e GPS. O datum foi arbitrado e os materiais foram identificados por meio de comparação com os previamente caracterizados na seção Hs18.

Foram coletadas amostras deformadas para análise granulométrica, isotópica do carbono e fitolítica, sendo esta última exclusivamente da seção Hs18. A granulometria foi determinada por peneiramento para a fração grossa e pipetagem para a fração fina, com separação via úmida utilizando-se CALGON (PAISANI, 1998). A análise isotópica do carbono da seção Hs18 foi realizada pelo Laboratório de Isótopos do Centro de Energia Nuclear na Agricultura (CENA-USP), enquanto que para a seção Hs12 foi realizada pelo Center for Applied Isotope Studies (Universidade da Georgia - USA), cujos resultados desta última foram obtidos de Paisani et al. (2014). A análise granulométrica, preparação de amostras para determinação isotópica do carbono e a extração de fitólitos foram realizadas no Laboratório de Análise de Formações Superficiais da Unioeste, sendo esta última conforme Paisani et al. (2016a). Já a classificação de morfotipos de fitólitos foi realizada no Laboratório de Microscopia Ótica da Unioeste. Para análise fitolítica foram estabelecidos índices de Cobertura Árborea (D/P), Áridez/Umidade(Iph), Climático (I/C) e de Estresse Hídrico (Bi), comumente utilizados em trabalhos de reconstrução paleoambiental (COE et al., 2014).

A geocronologia da matéria orgânica de níveis pedoestratigráfico da seção Hs 12 foi obtida de Paisani et al. (2014), os quais submeteram amostras dos horizontes $9 \mathrm{Cb}, 14 \mathrm{Ab}$ e $24 \mathrm{BC}$ para determinação da idade pelo ${ }^{14} \mathrm{C}$ (AMS) no Laboratório de Radiocarbono da Beta Analytic Inc. (USA). Já da seção Hs18 foi submetida amostra do nível $4 \mathrm{Cb}$ para determinação da idade pelo método de luminescência oticamente estimulada (LOE), com 15 alíquotas em grãos de quartzo, junto a empresa Datações, Comércio e Prestação de Serviços Ltda.

\section{Resultados}

\subsection{Pedoestratigrafia}

A seção Hs18 tem materiais de origem tanto coluvial quanto eluvial, os quais são substrato para 11 unidades pedoestratigráficas (horizontes $\mathrm{Ap}, 2 \mathrm{Bb}, 3 \mathrm{Cb}, 4 \mathrm{Ab}, 4 \mathrm{Cb}$, $5 \mathrm{Ab}, 5 \mathrm{Cb}, 6 \mathrm{Cb}, 7 \mathrm{ACb}, 8 \mathrm{Cb}$ e $9 \mathrm{CR} c g b$ ) (Figura 1B,C). As unidades apresentam textura da matriz variando de franco-argilo-siltosa a argilosa (Tabela 1), simplificadas em seção colunar em fácies lama ( $2 \mathrm{Bb}, 4 \mathrm{Cb}, 6 \mathrm{Cb}$ e $7 \mathrm{ACb})$, lama cascalhenta (8CAb) e conglomerado matriz suportada (3Cb e 5Cb) (Figura 1D). Tais fácies são decorrentes de fluxos de lama discretos gerados nas encostas que delimitam o setor de montante da rampa de colúvio (Figura 1B). Já os conglomerados com matriz suportada foram gerados por fluxos de detritos que misturaram fragmentos líticos em sua matriz. Seus materiais apresentam cores amarelo-avermelhadas a vermelho-amareladas e estrutura sedimentar maciça, porém a matriz exibe fraca estruturação pedológica de blocos, bem como consistência predominante dura (seca) e firme (úmida) (Tabela 1). Os níveis $7 \mathrm{ACb}$ e $8 \mathrm{CAb}$ são registros de horizontes superficiais enterrados e indicam pelo menos duas paleosuperfícies, cujo nível $8 \mathrm{Ab}$ está ausente em face a erosão (Figura 1C). Tais relações estratigráficas foram detectadas, sobretudo, pela análise fitolítica (item 4.4). No geral, os sedimentos coluviais apresentaram diferentes graus de pedogênese e foram truncados pela erosão. Diante disso, a espessura dos níveis pedoestratigráficos varia de 10 a 30 $\mathrm{cm}$, a exceção do horizonte 9CRcgb que apresenta 140 $\mathrm{cm}$ (Figura 1C, Tabela 1).

Tabela 1: Características morfológicas das unidades pedoestratigráficas da rampa de colúvioํ․

\begin{tabular}{|c|c|c|c|c|c|c|c|}
\hline Horizonte $^{2}$ & $\begin{array}{l}\text { Espessura } \\
(\mathrm{cm})\end{array}$ & Cor $^{3}$ & Textura $^{4}$ & Estrutura $^{5}$ & \multicolumn{2}{|c|}{ Consistência } & \multirow[t]{2}{*}{ Outras Características } \\
\hline & & & & & $\mathrm{Seca}^{6}$ & Úmida $^{7}$ & \\
\hline \multicolumn{8}{|c|}{ Seção Pedoestratigráfica Hs 18} \\
\hline Ap & 25 & 10YR $2 / 1$ & Franco-argilo-siltosa & $g-b s^{c}$ & $d$ & fi & $\begin{array}{c}\text { Raízes modernas, } \\
\text { compactado, }\end{array}$ \\
\hline $2 \mathrm{Bb}$ & 15 & 10YR 3/4 & Argilo-siltosa & $b s^{b}-p^{c}$ & $\mathrm{~d}$ & fi & - \\
\hline $3 \mathrm{Cb}$ & 10 & 10YR 5/4 & Argilo-siltosa & $\mathrm{m}$ & $\mathrm{d}$ & fr & Fragmentos líticos \\
\hline $4 \mathrm{Cb}$ & 10 & 7.5YR 5/6 & Argilosa & $\mathrm{m}-\mathrm{bs}^{\mathrm{c}}$ & $\mathrm{d}$ & fi & - \\
\hline
\end{tabular}


Dinâmica de Rampa de Colúvio na Superficie de Palmas/Água Doce Durante o Quaternário Tardio

\begin{tabular}{|c|c|c|c|c|c|c|c|}
\hline $5 \mathrm{Cb}$ & 20 & $7.5 \mathrm{YR} 5 / 6$ & Argilosa & $\mathrm{m}$ & $\mathrm{d}$ & fr & Fragmentos líticos \\
\hline $6 \mathrm{Cb}$ & 20 & 7.5 YR $5 / 6$ & Argilosa & $\mathrm{bs}^{\mathrm{c}}$ & $\mathrm{d}$ & $\mathrm{fr}$ & - \\
\hline $7 \mathrm{ACb}$ & 30 & 7.5YR 5/4 & Argilosa a argilo-siltosa & $\mathrm{m}-\mathrm{bs}^{\mathrm{c}}$ & $\mathrm{m}$ & $\mathrm{fr}$ & - \\
\hline $8 \mathrm{CAb}$ & 10 & $7.5 \mathrm{YR} 5 / 4$ & Argilosa & $\mathrm{m}-\mathrm{bs}^{\mathrm{c}}$ & $\mathrm{m}$ & fr & $\begin{array}{l}\text { Pedoturbação, fragmentos } \\
\text { líticos }\end{array}$ \\
\hline 9CRcgb & 130 & 5YR 5/8 & Argilosa & $\mathrm{m}$ & $\mathrm{m}$ & fr & $\begin{array}{c}\text { Concreções ferruginosas, } \\
\text { mosqueamento }\end{array}$ \\
\hline \multicolumn{8}{|c|}{ Seção Pedoestratigráfica Hs 12} \\
\hline Ap & 80 & 10YR 2/1 & Franco-argilo-siltosa & $\mathrm{bs}^{\mathrm{c}}-\mathrm{g}^{\mathrm{b}}$ & $\mathrm{d}$ & fr & $\begin{array}{l}\text { Clastos suportados de } \\
\text { grânulos a seixo a matriz } \\
\text { suportada }\end{array}$ \\
\hline $2 \mathrm{Cb}$ & 20 & $7.5 \mathrm{YR} 4 / 4$ & $\begin{array}{l}\text { Argilo-siltosa a Franco- } \\
\text { argilo-siltosa }\end{array}$ & $\mathrm{bs}^{\mathrm{c}}$ & $\mathrm{m}$ & fr & $\begin{array}{l}\text { Clastos suportados de } \\
\text { grânulos a seixo a matriz } \\
\text { suportada }\end{array}$ \\
\hline $3 \mathrm{Cb}$ & 15 & 7.5YR 4/4 & $\begin{array}{l}\text { Argilo-siltosa a Franco- } \\
\text { argilo-siltosa }\end{array}$ & $\mathrm{bs}^{\mathrm{c}}$ & $\mathrm{m}$ & fr & $\begin{array}{l}\text { Clastos de grânulos a } \\
\text { seixo, matriz suportada }\end{array}$ \\
\hline $4 \mathrm{Cb}$ & 80 & $10 \mathrm{YR} 4 / 4$ & Argilo-siltosa & $\mathrm{bs}^{\mathrm{c}}$ & $\mathrm{m}$ & fr & - \\
\hline $5 \mathrm{Cb}$ & 20 & $7.5 \mathrm{YR} 4 / 4$ & $\begin{array}{l}\text { Argilo-siltosa a Franco- } \\
\text { argilo-siltosa }\end{array}$ & $\mathrm{bs}^{\mathrm{c}}$ & $\mathrm{m}$ & fr & $\begin{array}{l}\text { Clastos suportados de } \\
\text { grânulos a seixo a matriz } \\
\text { suportada }\end{array}$ \\
\hline $6 \mathrm{Cb}$ & 65 & $10 Y R 4 / 4$ & Franco-argilo-siltosa & $\mathrm{bs}^{\mathrm{c}}$ & $\mathrm{m}$ & fr & $\begin{array}{l}\text { Clastos suportados de } \\
\text { grânulos a seixo a matriz } \\
\text { suportada }\end{array}$ \\
\hline $7 \mathrm{Cb}$ & 20 & $7.5 \mathrm{YR} 4 / 4$ & $\begin{array}{l}\text { Argilo-siltosa a Franco- } \\
\text { argilo-siltosa }\end{array}$ & $\mathrm{bs}^{\mathrm{c}}$ & $\mathrm{m}$ & fr & - \\
\hline $8 \mathrm{Cb}$ & 50 & $7.5 \mathrm{YR} 4 / 4$ & $\begin{array}{l}\text { Argilo-siltosa a Franco- } \\
\text { argilo-siltosa }\end{array}$ & $\mathrm{bs}^{\mathrm{c}}$ & $\mathrm{m}$ & fr & $\begin{array}{l}\text { Clastos suportados de } \\
\text { grânulos a seixo a matriz } \\
\text { suportada }\end{array}$ \\
\hline $9 \mathrm{Cb}$ & 30 & $7.5 \mathrm{YR} 4 / 4$ & Franco-argilo-siltosa & $\mathrm{bs}^{\mathrm{c}}$ & $\mathrm{m}$ & fr & $\begin{array}{l}\text { Clastos de grânulos a } \\
\text { seixo, matriz suportada }\end{array}$ \\
\hline $10 \mathrm{Cb}$ & 20 & 10YR 4/4 & Argilo-siltosa & $\mathrm{bs}^{\mathrm{c}}$ & $\mathrm{m}$ & fr & $\begin{array}{l}\text { Clastos suportados de } \\
\text { grânulos a seixo a matriz } \\
\text { suportada }\end{array}$ \\
\hline $11 \mathrm{Cb}$ & 5 & $7.5 \mathrm{YR} 4 / 4$ & $\begin{array}{l}\text { Argilo-siltosa a Franco- } \\
\text { argilo-siltosa }\end{array}$ & $\mathrm{bs}^{\mathrm{c}}$ & $\mathrm{m}$ & fr & $\begin{array}{l}\text { Clastos suportados de } \\
\text { grânulos a seixo }\end{array}$ \\
\hline $12 \mathrm{Ab}$ & 15 & 10YR $3 / 3$ & Argilo-siltosa & $b s^{b}$ & d-m & fi & $\begin{array}{c}\text { Traços de raízes, Clastos } \\
\text { de grânulos a seixo a } \\
\text { matriz suportada }\end{array}$ \\
\hline $12 \mathrm{Cb}$ & 15 & $7.5 \mathrm{YR} 4 / 4$ & $\begin{array}{l}\text { Argilo-siltosa a Franco- } \\
\text { argilo-siltosa }\end{array}$ & $\mathrm{bs}^{\mathrm{c}}$ & $\mathrm{m}$ & fr & $\begin{array}{l}\text { Clastos de grânulos a } \\
\text { seixo a matriz suportada }\end{array}$ \\
\hline $13 \mathrm{Cb}$ & 10 & $7.5 Y R 4 / 4$ & $\begin{array}{l}\text { Argilo-siltosa a Franco- } \\
\text { argilo-siltosa }\end{array}$ & $\mathrm{bs}^{\mathrm{c}}$ & $\mathrm{m}$ & fr & $\begin{array}{l}\text { Clastos suportados de } \\
\text { grânulos a seixo }\end{array}$ \\
\hline $14 \mathrm{Ab}$ & 15 & $10 \mathrm{YR} 2 / 2$ & Argiloso & $\mathrm{bs}^{\mathrm{b}}$ & $d-m$ & fi & Traços de raízes \\
\hline $14 \mathrm{Cb}$ & 10 & $7.5 Y R 3 / 3$ & $\begin{array}{l}\text { Argilo-siltosa a Franco- } \\
\text { argilo-siltosa }\end{array}$ & $\mathrm{bs}^{\mathrm{c}}$ & $\mathrm{m}$ & $\mathrm{fr}$ & $\begin{array}{l}\text { Clastos suportados de } \\
\text { grânulos a seixo a matriz } \\
\text { suportada }\end{array}$ \\
\hline $15 \mathrm{Cb}$ & 5 & $7.5 Y R 4 / 4$ & $\begin{array}{l}\text { Argilo-siltosa a Franco- } \\
\text { argilo-siltosa }\end{array}$ & $\mathrm{bs}^{\mathrm{c}}$ & $\mathrm{m}$ & $\mathrm{fr}$ & $\begin{array}{l}\text { Clastos suportados de } \\
\text { grânulos a seixo }\end{array}$ \\
\hline $16 \mathrm{Cb}$ & 50 & $7.5 Y R 4 / 4$ & Franco-argilo-siltosa & $\mathrm{bs}^{\mathrm{c}}$ & $\mathrm{m}$ & fr & - \\
\hline $17 \mathrm{Cb}$ & 15 & $7.5 \mathrm{YR} 4 / 4$ & Argilo-siltosa & $\mathrm{bs}^{\mathrm{c}}$ & $\mathrm{m}$ & fr & $\begin{array}{l}\text { Clastos suportados de } \\
\text { grânulos a seixo }\end{array}$ \\
\hline
\end{tabular}


Paisani J. C. et al.

\begin{tabular}{|c|c|c|c|c|c|c|c|}
\hline $18 \mathrm{Cb}$ & 25 & $7.5 \mathrm{YR} 4 / 4$ & Argilo-siltosa & $\mathrm{bs}^{\mathrm{c}}$ & $\mathrm{m}$ & fr & $\begin{array}{l}\text { Clastos de grânulos a } \\
\text { seixo, matriz suportada }\end{array}$ \\
\hline $19 \mathrm{Ab}$ & 10 & $7.5 \mathrm{YR} 3 / 3$ & Argiloso a Argilo-siltosa & $\mathrm{bs}^{\mathrm{b}}$ & $d-m$ & fi & $\begin{array}{l}\text { Traços de raízes e de } \\
\text { pedoturbação }\end{array}$ \\
\hline $19 \mathrm{Cb}$ & 10 & $7.5 Y R 3 / 4$ & Argilo-siltosa & $\mathrm{bs}^{\mathrm{c}}$ & $\mathrm{m}$ & fr & - \\
\hline $20 \mathrm{Cb}$ & 25 & $7.5 \mathrm{YR} 4 / 4$ & $\begin{array}{l}\text { Argilo-siltosa a Franco- } \\
\text { argilo-siltosa }\end{array}$ & $\mathrm{bs}^{\mathrm{c}}$ & $\mathrm{m}$ & fr & Clastos de grânulo a seixo \\
\hline $21 \mathrm{Cb}$ & 5 & $7.5 \mathrm{YR} 4 / 4$ & $\begin{array}{c}\text { Argilo-siltosa a Franco- } \\
\text { argilo-siltosa }\end{array}$ & $\mathrm{bs}^{\mathrm{c}}$ & $\mathrm{m}$ & fr & $\begin{array}{l}\text { Clastos suportados de } \\
\text { grânulos a seixo }\end{array}$ \\
\hline $22 \mathrm{Cb}$ & 25 & $7.5 \mathrm{YR} 4 / 4$ & $\begin{array}{l}\text { Argilo-siltosa a Franco- } \\
\text { argilo-siltosa }\end{array}$ & $\mathrm{bs}^{\mathrm{c}}$ & $\mathrm{m}$ & fr & Clastos de grânulo a seixo \\
\hline $23 \mathrm{Ab}$ & 10 & $7.5 \mathrm{YR} 3 / 3$ & Argiloso & $\mathrm{bs}^{\mathrm{b}}$ & $\mathrm{d}$ & fi & Traços de raízes \\
\hline $23 \mathrm{Cb}$ & 15 & 7.5YR 4/4 & Argilo-siltosa & & $\mathrm{m}$ & fr & \\
\hline $24 \mathrm{BCb}$ & 15 & $7.5 \mathrm{YR} 4 / 6$ & Argilo-siltosa & $b s^{b}-p^{c}$ & $\mathrm{~m}$ & $\mathrm{fr}$ & Traços de raízes e carvões \\
\hline $24 \mathrm{Cb}$ & 60 & $7.5 \mathrm{YR} 4 / 6$ & $\begin{array}{c}\text { Argilo-siltosa a Franco- } \\
\text { argilo-siltosa }\end{array}$ & $\mathrm{bs}^{\mathrm{c}}$ & $\mathrm{m}$ & fr & $\begin{array}{c}\text { Clastos de grânulo a seixo } \\
\text { matriz suportada }\end{array}$ \\
\hline $25 \mathrm{Cb}$ & 20 & $5 \mathrm{YR} 4 / 6$ & $\begin{array}{l}\text { Argilo-siltosa a Franco- } \\
\text { argilo-siltosa }\end{array}$ & $\mathrm{bs}^{\mathrm{c}}$ & $\mathrm{m}$ & $\mathrm{fr}$ & $\begin{array}{l}\text { Localmente clastos } \\
\text { suportados de grânulo a } \\
\text { seixo }\end{array}$ \\
\hline $26 \mathrm{Cb}$ & 45 & $7.5 \mathrm{YR} 4 / 4$ & $\begin{array}{l}\text { Argilo-siltosa a Franco- } \\
\text { argilo-siltosa }\end{array}$ & $\mathrm{bs}^{\mathrm{c}}$ & $\mathrm{m}$ & $\mathrm{fr}$ & - \\
\hline
\end{tabular}

${ }^{1}$ Informações obtidas de Paisani et al. (2014), Oliveira (2014) e Paisani (2015). ${ }^{2}$ A:horizonte superficial mineral com matéria orgânica suficiente para lhe imprimir cores escuras, AC:horizonte de transição dominado pelas características do horizonte A, CA:horizonte de transição dominado pelas características do horizonte C, B:horizonte mineral subsuperficial cujas características, sobretudo estruturais, são atribuídas a processos pedogenéticos, C:material parental, cujos processos pedogenéticos são incipientes, R: rocha inconsolidada com pouca evidência de intemperismo, CR:horizonte de transição com características predominantes do horizonte C, b:enterrado, c:concreções ou nódulos, g:glei (hidromórfico) (CURI et al., 1993; BRANDY eWEIL, 2013). ${ }^{3}$ Segundo Carta de Munsell. ${ }^{4}$ Diagrama triangular da USDA(SCHAETZL e ANDERSON, 2005). ${ }^{5}$ g:granular, bs:blocos subangulares, p:prismática, grau de desenvolvimento forte ${ }^{\mathrm{a}}$, médio $^{\mathrm{b}}$, fraca ${ }^{\mathrm{c}}$, m:maciça. $^{6} \mathrm{~d}: \mathrm{dura}$, m:macia, s:solta. ${ }^{7}$ fi:firme, fr:friável.

A topossequencia estabelecida perpendicularmente a seção Hs 18 revelou afloramento de riolito mantendo os terços superior e intermediário da rampa de colúvio (Figura 2), enquanto sedimentos coluviais se encontram ao longo de seu terço inferior. Os terços superior e intermediário são os locais fonte de sedimentos coluviais, ao passo que o terço inferior revelou paleocanal de drenagem de baixa ordem e a extensão lateral do horizonte 9CRcgb (Figura 2). Acredita-se que se trata de paleocanal de $1^{\text {a }}$ ordem, estabelecido perpendicular a rampa, que foi colmatado por sedimentos coluviais (Figura 2A). Após o soterramento o paleocanal continuou a drenar os materiais em condições hipodérmicas, como evidenciam horizontes hidromórficos ( $\mathrm{Cg}$ e $\mathrm{CRg}$ ) a partir dos sedimentos de sua base (Figura 2B).

O horizonte 9CRcgb se destaca justamente por ser hidromórfico com concreção ferruginosa centimétrica (Figura 3). A topossequencia revelou que a concreção desaparece tanto nos limites do paleocanal de drenagem (Figura 2), quanto em direção a seção Hs12. Esse nível hidromórfico é remanescente de fase em que o paleocanal apresentava talvegue menos incisivo e migração de óxidos e hidróxidos lateralmente a partir das encostas antes do estabelecimento dos materiais coluviais (THOMAS, 1994). Esses fatos são importantes, pois mostram o reafeiçoamento da paisagem ao longo do tempo e que o fenômeno de colmatação de fundos de vales de baixa ordem ocorreu em detrimento do estabelecimento de rampas de colúvio.

A seção Hs 12 revelou materiais de origem tanto coluvial quanto aluvial, os quais são substrato para 32 unidades pedoestratigráficas (horizontes $\mathrm{Ap}, 2 \mathrm{Cb}$, $3 \mathrm{Cb}, 4 \mathrm{Ab}, 4 \mathrm{Cb}, 5 \mathrm{Cb}, 6 \mathrm{Cb}, 7 \mathrm{Cb}, 8 \mathrm{Cb}, 9 \mathrm{Cb}, 10 \mathrm{Cb}$, $11 \mathrm{Cb}, 12 \mathrm{Ab}, 12 \mathrm{Cb}, 13 \mathrm{CB}, 14 \mathrm{Ab}, 14 \mathrm{Cb}, 15 \mathrm{Cb}, 16 \mathrm{Cb}$, $17 \mathrm{Cb}, 18 \mathrm{Cb}, 19 \mathrm{Ab}, 19 \mathrm{Cb}, 20 \mathrm{Cb}, 21 \mathrm{Cb}, 22 \mathrm{Cb}, 23 \mathrm{Ab}$, $23 \mathrm{Cb}, 24 \mathrm{BCb}, 24 \mathrm{Cb}, 25 \mathrm{Cb}$ e $26 \mathrm{Cb}$ ) (Figura 1B,C). As unidades apresentam matriz com textura variando de franco-argilo-siltosa a argilo-siltosa (Tabela 1), simplificadas em seção colunar em fácies lama $(2 \mathrm{Cb}$ a $6 \mathrm{Cb}$, $8 \mathrm{Cb}, 9 \mathrm{Cb}, 11 \mathrm{Cb}, 14 \mathrm{Cb}, 17 \mathrm{Cb}, 20 \mathrm{Cb}$ a $22 \mathrm{Cb}$ e $25 \mathrm{Cb}) \mathrm{e}$ lama cascalhenta $(7 \mathrm{Cb}, 10 \mathrm{Cb}, 12 \mathrm{Cb}, 13 \mathrm{Cb}, 15 \mathrm{Cb}, 16 \mathrm{Cb}$, $18 \mathrm{Cb}, 19 \mathrm{Cb}, 23 \mathrm{Cb}$ a $24 \mathrm{Cb}$ e $26 \mathrm{Cb}$ ) (Figura 1D). Tais fácies são decorrentes de fluxos de lama gerados nas 
encostas que colmataram paleocanal de baixa ordem que seccionava longitudinalmente a rampa de colúvio. Trata-se de paleocanal similar ao encontrado na topossequencia (Figura 2A). Esse paleocanal foi reativado parcialmente, constituindo moderno canal de $1^{\mathrm{a}}$ ordem desconectado da rede de drenagem que se estende pelos terços intermediário e superior da rampa de colúvio com dois níveis de knickpoint (Figura 2A).

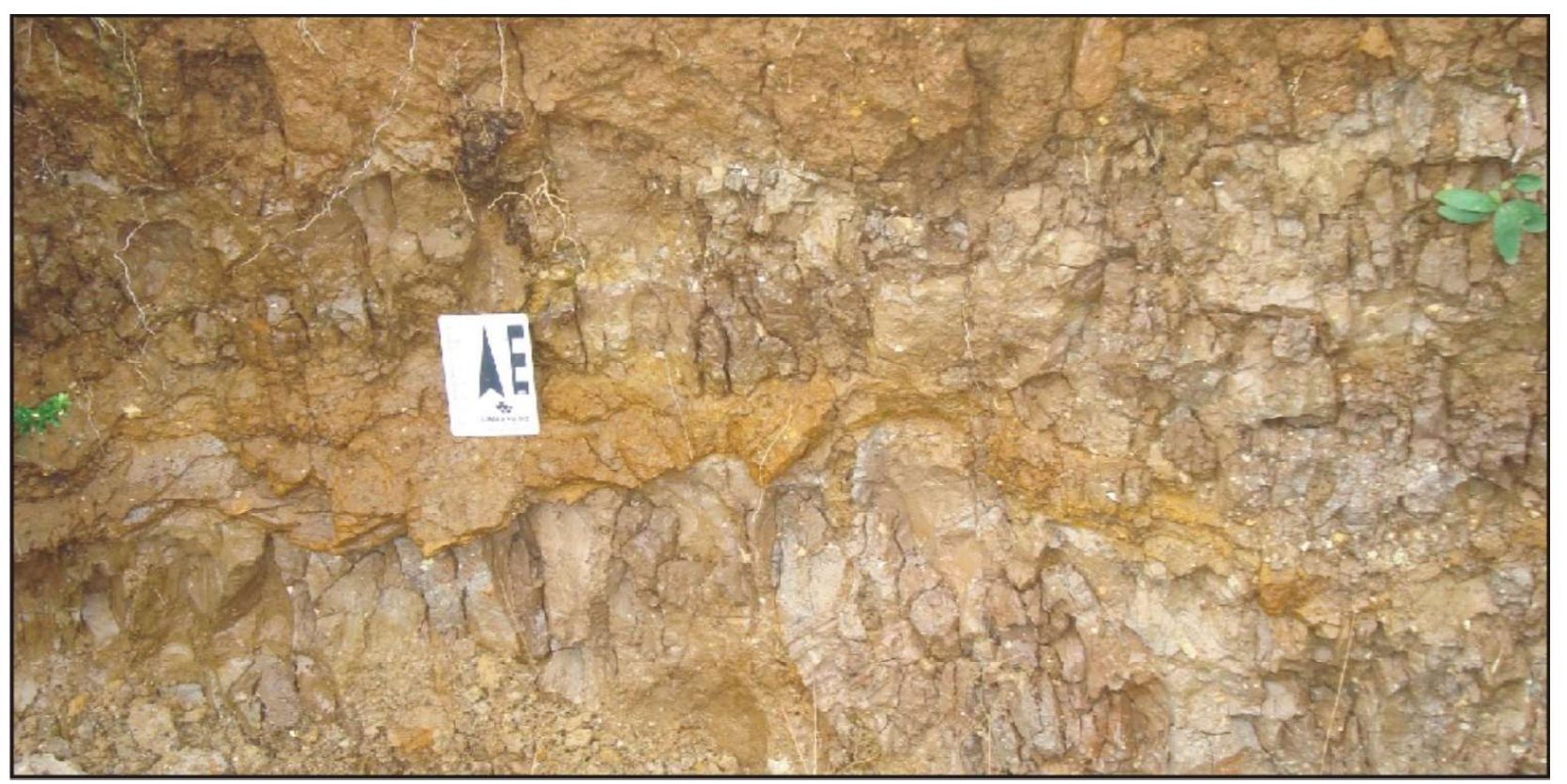

Figura 3 - Concreção ferruginosa caracterizada por morfologia tabular, em seu topo, e ondulada, na sua base, estabelecida no horizonte 9CRcgb.

As fácies aluviais do registro estratigráfico foram geradas pelo referido canal de drenagem e mantém as unidades pedoestratigráficas $11 \mathrm{Cb}$ a Ap (Figura 1D). Nelas são comuns estruturas de corte e preenchimento associadas a fluxos hiperconcentrados decorrentes da dinâmica fluvial do atual canal de $1^{\mathrm{a}}$ ordem desconectado da rede de drenagem (base dos horizontes $8 \mathrm{Cb}$, $6 \mathrm{Cb}, 5 \mathrm{Cb}, 4 \mathrm{Cb}$ e Ap - Figura 1D) (OLIVEIRA, 2014). No geral, os materiais tem cores amarelo-avermelhadas a vermelho-amareladas próximas aos dos materiais da seção Hs18 (Tabela 1). Eles apresentam estrutura sedimentar maciça, porém a matriz exibe fraca estruturação pedológica de blocos, bem como consistência predominante macia (seca) e firme (úmida). A sequência pedoestratigráfica passou por pedogênese progressiva na conceituação de Johnson et al. (1990), como documentam os horizontes $12 \mathrm{Ab}, 14 \mathrm{Ab}, 19 \mathrm{Ab}, 23 \mathrm{Ab}$ e $24 \mathrm{BCb}$ (Figura 1D, Tabela 1). Eles representam fase de estabilidade ambiental local pontuada por eventos de erosão e sedimentação que acarretou no escalonamento de paleossolos enterrados, cuja ocorrência no registro pedoestratigráfico pode ser designada de pedocomplexo ou paleossolos compostos (PAISANI et al., 2014).

\subsection{Geocronologia e Correlação Estratigráficas}

As idades obtidas por ${ }^{14} \mathrm{C}$ através da matéria orgânica contida em sedimento organo-mineral fácies aluvial (horizonte $9 \mathrm{Cb}$ ), em paleossolo (horizonte 14AB) e de carvões em remanescente de horizonte $\mathrm{BC}$ (hrizonte $24 \mathrm{BCb}$ ) da seção Hs12 foram, respectivamente, de $19.840 \pm 80$ anos AP (23.880 a 23.500 anos cal. AP), $23.800 \pm 50$ anos AP (28.060 a 29.080 anos cal. AP) e $28.880 \pm 160$ anos AP (33.860 a 33.030 anos cal. AP) (Tabela 2). As idades dos horizontes $24 \mathrm{BCb}$ e $14 \mathrm{Ab}$ sugerem que o pedocomplexo (horizontes 24BCb, 23Ab, 19Ab, 14Ab e 12Ab) está em fase cronológica com o período paleoclimático global conhecido como Último Interestadial (Estágio Isotópico Marinho 3 - EIM 3) (LONG e STOY, 2013). Tais níveis pedoestratigráficos apresentam correlação pedoestratigráfica e cronológica com outros paleossolos identificados em paleofundos de vales de baixa ordem na área de estudo, desenvolvidos durante esse período (PAISANI et al., 2014). Na seção Hs 18 os níveis pedoestratigráficos $8 \mathrm{CAb}$ e 7CAb são interpretados como correlatos dessa fase de pedogênese (Figura 4). 
Tabela 2: Idades ${ }^{14} \mathrm{C}$ e Luminescência Oticamente Estimulada (LOE) dos registros estratigráficos das seções Hs12 e Hs18.

\begin{tabular}{|c|c|c|c|c|c|c|c|c|}
\hline \multicolumn{9}{|c|}{${ }^{14} C^{*}$ - Seção Hs12 } \\
\hline Horizonte & Local & Cód.Lab. & \multicolumn{2}{|c|}{ Idade (anos $\left.{ }^{14} \mathrm{C} \mathrm{AP}\right)$} & \multicolumn{3}{|c|}{ Idade (anos cal. $\left.{ }^{14} \mathrm{C} \mathrm{AP}\right)^{*}$} & $\delta^{13} \mathbf{C}(\%)$ \\
\hline $9 \mathrm{Cb}^{1}$ & Centro & $351570^{3}$ & \multicolumn{2}{|c|}{$19.840 \pm 80$} & \multicolumn{3}{|c|}{$23.880-23.500$} & $-19,60$ \\
\hline $14 \mathrm{Ab}$ & Centro & $8876^{4}$ & \multicolumn{2}{|c|}{$23.800 \pm 50$} & \multicolumn{3}{|c|}{$28.060-29.080$} & $-22,90$ \\
\hline $24 \mathrm{BCb}^{2}$ & Topo & $351569^{3}$ & \multicolumn{2}{|c|}{$28.880 \pm 160$} & \multicolumn{3}{|c|}{$33.860-33.030$} & $-24,60$ \\
\hline \multicolumn{9}{|c|}{ Luminescência Oticamente Estimulada (LOE) - Seção Hs18 } \\
\hline Horizonte & Local & Cód.Lab. & Th (ppm) & $\mathbf{U}(\mathbf{p p m})$ & K (\%) & $\begin{array}{l}\text { Dose Anual } \\
\left(\mu \mathrm{Gy} \cdot \mathbf{a n o}^{-1}\right)\end{array}$ & $P(G y)$ & $\begin{array}{c}\text { Idade } \\
\text { (anos A.P.) }\end{array}$ \\
\hline $4 \mathrm{Cb}$ & base & 4201 & $20,97 \pm 0,76$ & $5,71 \pm 0,40$ & $0,65 \pm 0,1$ & $3.740 \pm 255$ & 73,93 & $19.770 \pm 2.350$ \\
\hline
\end{tabular}

* Idades obtidas de Paisani et al. ( 2014) e calibradas com $2 \sigma, 95 \%$ de probabilidade ${ }^{1}$ Sedimento organo-mineral. ${ }^{2}$ Carvão. ${ }^{3}$ Beta Analtic Inc. ${ }^{4}$ Center for Applied Isotope Studies (University of Georgia-USA).

A idade do nível $9 \mathrm{Cb}$ da seção Hs12 equivale ao período do Último Máximo Glacial, ou EIM 2 (Tabela 2). Acredita-se que os sedimentos coluviais que mantém nos níveis $11 \mathrm{Cb}$ e $10 \mathrm{Cb}$ também foram gerados nessa época, justamente após o desenvolvimento do horizonte $12 \mathrm{Ab}$, topo do pedocomplexo (Figura 4). A cronologia do nível 9 Cb tem correlação cronológica com o nível $4 \mathrm{Cb}$ da seção Hs18 (Figura 4). Esse nível pedoestratigráfico se encontra entre dois níveis conglomeráticos com matriz suportada (3Cb e $5 \mathrm{Cb}$ ), cuja característica sedimentológica destoa em relação aos demais níveis pedoestratigráficos da seção Hs18. A idade de $19.770 \pm 80$ anos AP do nível $4 \mathrm{Cb}$ da seção Hs 18 sugere que sua sequência pedoestratigráfica $(3 \mathrm{Cb}$ a $5 \mathrm{Cb})$ foi gerada durante o Último Máximo Glacial, e apresentaria correlação cronoestratigráfica com a sequência $11 \mathrm{Cb}$ a $9 \mathrm{Cb}$ da seção Hs12 (Figura 4). Já os níveis pedoestratigráficos sobrejacentes estabelecidos sobre facies aluviais na seção Hs12 (8Cb a Ap) são interpretados como situados durante o Holoceno, ou EIM1, assim como as fácies coluviais em que se estabeleceram os níveis 2Bb e Ap da seção Hs18 (Figura 4). No geral, percebe-se que a morfogênese atuou continuamente na área de estudo entre o Último Interestadial e o Holoceno, com favorecimento da pedogênese no final do primeiro, similarmente ao encontrado em outras seções pedoestratigráficas representativas de paleofundos de vales de baixa ordem na superfície de Palmas/Água Doce (PAISANI et al., 2012; 2014; 2016b; GUERRA e PAISANI, 2013; LIMA, 2016; RIBEIRO, 2016).

\subsection{Composição Isotópica do Carbono}

O carbono total das unidades pedoestratigráfica da seção Hs18 ficou entre 5,89 a 0,73\% (PAISANI, 2015), ao passo que os valores do $\delta \mathrm{C}-13$ variaram de $-13,12$ a -19,80\% (Figura 4). A distribuição dessa razão isotópica torna-se mais negativa com a profundidade, havendo mudança de $\sim 6 \%$ entre os níveis mais superficiais (Ap e $2 \mathrm{Bb}$ ) e os mais profundos (6Cb a 8CAb) (Figura 4). Os valores mais negativos são registrados justamente nos níveis mais profundos, $8 \mathrm{CAb}(-19,80 \%), 7 \mathrm{CAb}(-19,37 \%)$ e base do $6 \mathrm{Cb}(-19,43 \%$ ). Já nos níveis mais superficiais, Ap $(-13,12 \%)$ e $2 \mathrm{Bb}(-13,33 \%)$ os valores são menos negativos. Os valores dos níveis superficiais apontam para o predomínio de plantas com padrão fotossintético $\mathrm{C}_{4}$ (gramíneas - maioria das Poaceae), pois elas apresentam razão isotópica entre -17 a -9\%o (PESSENDA et al., 1996; 2005). Enquanto que nos níveis mais profundos, sobretudo nos horizontes $6 \mathrm{Cb}$ a $8 \mathrm{CAb}$, os valores sugerem mistura de plantas $\mathrm{C}_{3} \mathrm{eC}_{4}$ uma vez que plantas $\mathrm{C}_{3}$ (arbustos, arbóreas e algumas Poaceae) tem razão isotópica de $-32 \mathrm{a}-22 \%$ (PESSENDA et al., 1996; 2005). A sutil variação dos valores para mais negativos pode refletir a mistura de matéria orgânica de Poaceae com espécies arbustivas (Baccharis caprariifolia DC e Eryngium pandanifolium), como é verificado nas áreas de campo moderno em regeneração (PAISANI et al., 2013), ou presença de gramíneas $\mathrm{C}_{3}$.

Na seção Hs12 o registro isotópico segue a tendência verificada para a seção vizinha, diferindo em relação a extensão vertical do sinal isotópico das plantes $\mathrm{C}_{4}$, que ocorrem dos níveis $\mathrm{Ap}$ ao $8 \mathrm{Cb}$ (Figura 2). A partir desse último registra-se uma tendência de mistura com matérias orgânica de plantas $\mathrm{C}_{3}$ com a profundidade, a qual se efetiva nos níveis subjacentes $10 \mathrm{Cb}$ a $12 \mathrm{Cb}$. Apenas o nível $14 \mathrm{Ab}$ apresenta valor sugestivo para plena ocorrência de plantas $\mathrm{C}_{3}$. Nos $15 \mathrm{Cb}$ a $18 \mathrm{Cb}$ há predomínio dessa categoria de vegetação, porém ainda na faixa de mistura. Com base em valores isotópicos obtidos em ambiente florestal moderno, Paisani et al. (2014) sugerem que entre os níveis $9 \mathrm{Cb}$ e $23 \mathrm{Cb}$ havia o predomínio de floresta, talvez mais aberta que nas condições modernas. 


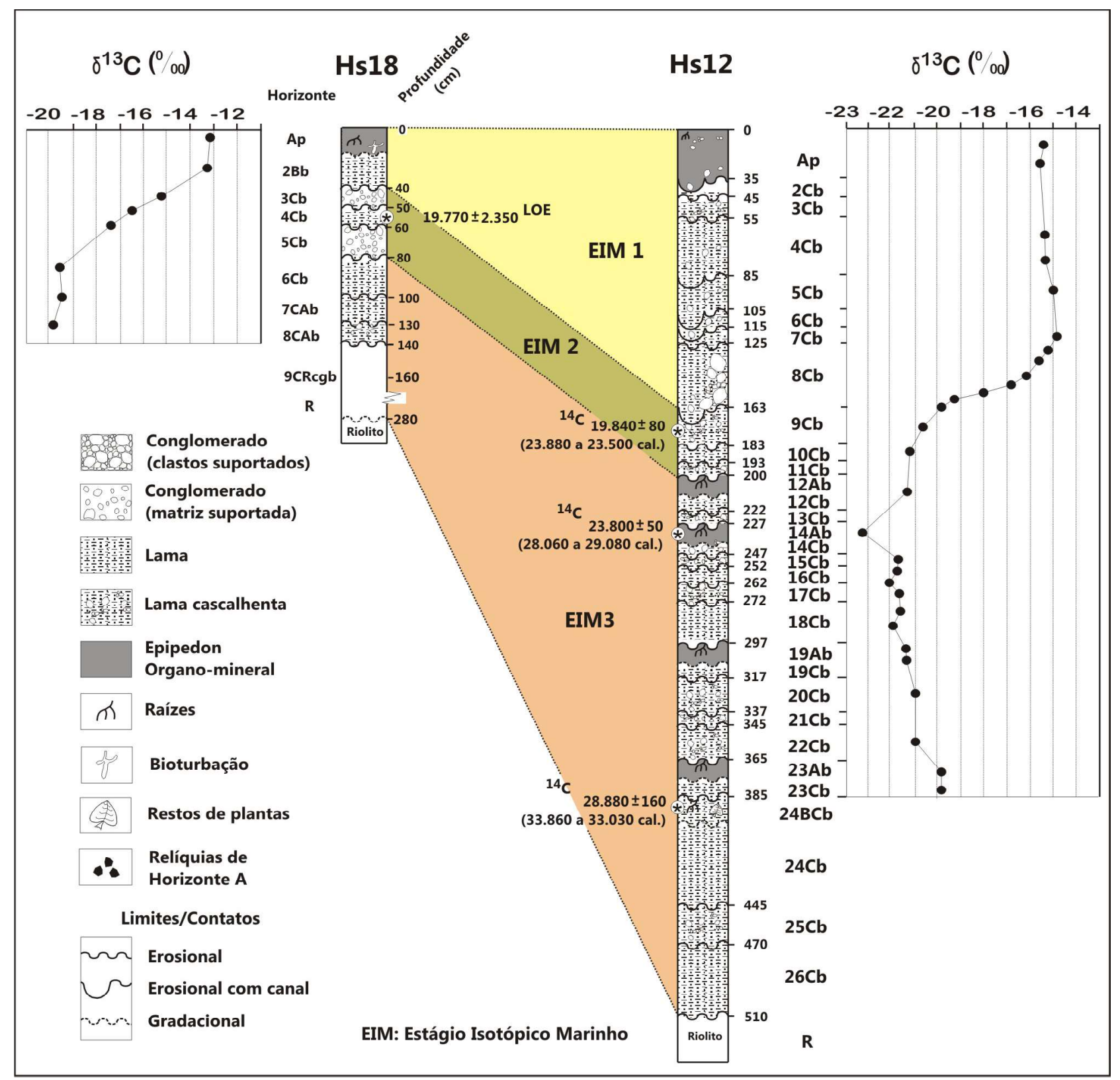

Figura 4 - Correlação entre niveis pedoestratigráficos das seções Hs 18 e Hs12, bem como respectivos conteúdos isotópicos do carbono (modificado de PAISANI, 2014; 2015).

Comparando os sinais isotópicos do carbono de ambas as seções percebe-se que é comum a presença de matéria orgânica derivada de plantas $\mathrm{C}_{4}$ nos níveis do Holoceno (EIM 1) em ambas as seções, com tendência de mistura nos níveis pedoestratigráficos estabelecidos durante o Último Máximo Glacial (EIM2) e Último Interestádio (EIM3) (Figura 2). Por outro lado, os sinais isotópicos sugerem que na seção Hs12 predominou vegetação mais exuberante em plantas $\mathrm{C}_{3}$ durante a colmatação dos paleofundos de vale.

\subsection{Análise fitolítica (seção Hs18)}

A concentração de fitólitos no registro pedoestratigráfico variou de 1,14 a $34,38 \%$, sendo que nos primeiros $30 \mathrm{~cm}$ de profundidade, entre os horizontes Ap e $2 \mathrm{Bb}$ topo, ocorrem os maiores percentuais (Figura 5). Próximo à superfície, o horizonte Ap apresenta um total de $\sim 34,00 \%$ de fitólitos. Já o horizonte $2 \mathrm{Bb}$ registra substancial redução com valores que decrescem de 18,37 para 11,52\% (Figura 5). Essa elevada concentra- 
ção de fitólitos no horizonte Ap está em acordo com a proximidade da fonte moderna de fitólitos, vegetação e fezes de bovinos. A partir do horizonte $2 \mathrm{Bb}$ há redução da concentração de fitólitos conforme a profundidade, havendo picos de maior concentração nos horizontes $5 \mathrm{Cb}$ base, $6 \mathrm{Cb}$ topo, 7ACB topo e 8CAb (Figura 5).
Essas maiores concentrações indicam dois fenômenos: 1) proximidade à antigas superfícies truncadas pela erosão, no caso dos horizontes $2 \mathrm{Bb}, 7 \mathrm{ACB}$ e $8 \mathrm{CAb}$; e 2) mistura de fitólitos de níveis pedoestratigráficos sotapostos, como no caso da base do horizonte $5 \mathrm{Cb}$ e topo do $6 \mathrm{Cb}$.

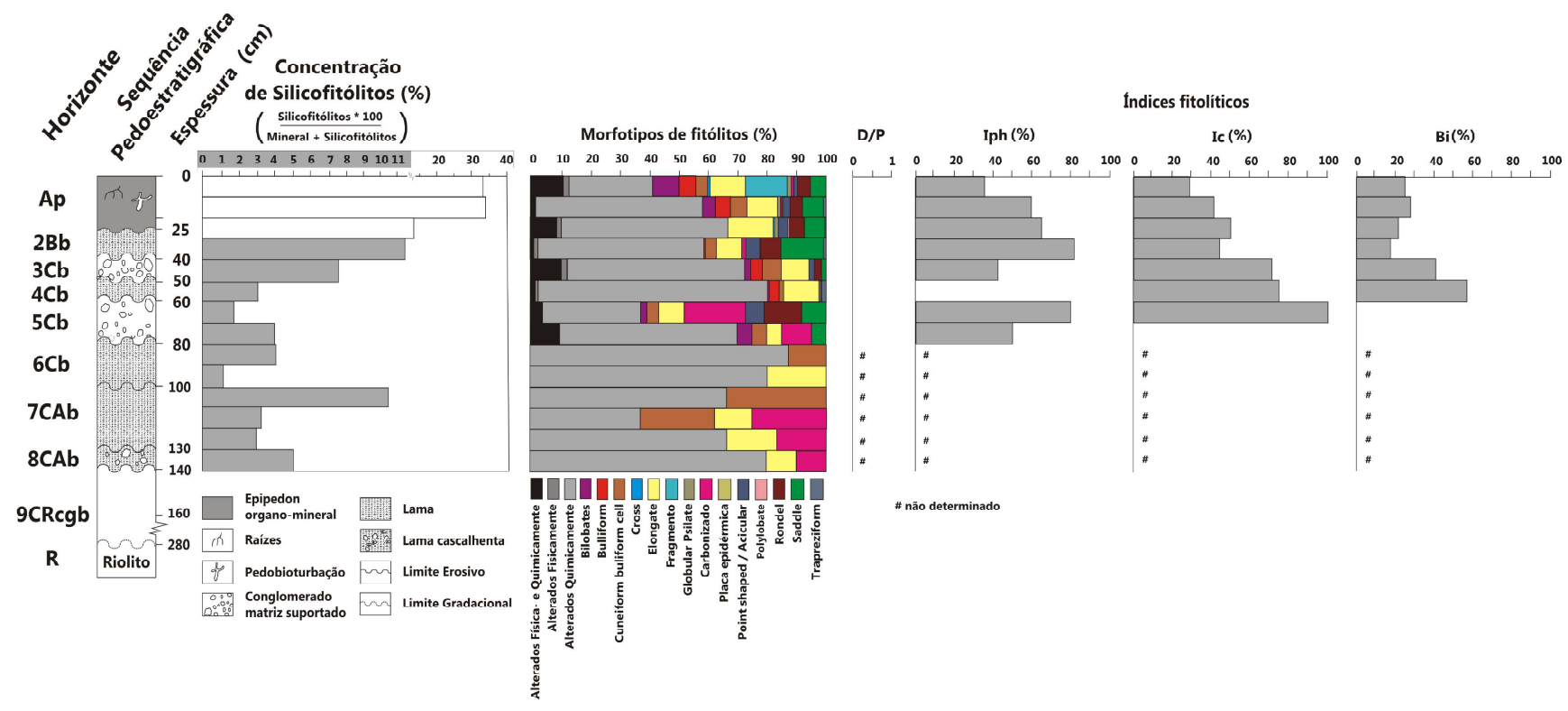

Figura 5 - Concentração, morfotipos e índices de fitolíticos do registro pedoestratigráfico da rampa de colúvio (adaptado de PAISANI, 2015).

A análise de morfotipos revela um total de 1396 fitólitos, com destaque para aqueles com significado taxonômico de gramínea (Poaceae): Bilobate, Bulliform, Saddle, Cuneiform Bulliform Cell, Rondel, Point Shaped, Trapeziform, Polylobate e Cross (Figura 5). Além destes são encontrados outros morfotipos que não foram identificados em face da degradação física e/ou química, pequenos fragmentos e fitólitos carbonizados.

A degradação física e química da morfologia dos fitólitos para a área de estudo está vinculada ao processo de mastigação de animais herbívoros durante a pastagem, em face de seu desprendimento dos bolos fecais estabelecidos tanto sobre a superfície moderna (gado) quanto sobre paleosuperfícies (PAISANI, 2015). Neste último caso, deriva da paleofauna herbívora do Pleistoceno (PAISANI et al., 2016b). Já a degradação química resulta tanto do processo digestivo de animais herbívoros quanto por processos biogeoquímicos, associados à pedogênese ou diagênese, promovendo a decomposição dos fitólitos estabelecidos no registros pedoestratigráficos (PAISANI et al., 2016b).

Os fitólitos carbonizados também são degradados, porém mediante a queima, e assumem significado ambien- tal simplesmente por evidenciar fases em que as plantas foram submetidas ao fogo. Esta categoria ocorre nos três primeiros centímetros do horizonte $\mathrm{Ap}$, bem como no $2 \mathrm{Bb}$ (base), $5 \mathrm{Cb}, 7 \mathrm{ACb}$ (base) e 8CAb (Figura 5). Os fitólitos carbonizados do horizonte Ap decorrem das periódicas queimadas promovidas pela ação antrópica como meio de manejo moderno da área de estudo para o pastoreio (PAISANI et al., 2016a). Ao passo que sua presença nos demais níveis tem sido interpretada como resultante tanto de incêndios provocados por índios antes da colonização no século XIX (paleoíndios), quanto por incêndios naturais comuns a superfícies geomórficas similares do Sul do Brasil (BEHLING, 1997; BEHLING et al., 2004; JESKE-PIERUSCHKA et al., 2010; PAISANI et al., 2013). A presença de fitólitos carbonizados nos níveis mais profundos (horizontes $6 \mathrm{Cb}$ e $8 \mathrm{CAb}$ ), deve ser exclusivamente relacionada a este último fator.

A respeito dos índices fitolíticos o D/P resultou no valor de zero (Figura 5), o qual reflete formação vegetal de Campo (BREMOND et al., 2005). O Iph variou entre 0 a 83,33\% nos níveis pedoestratigráficos (Figura 5), cujos valores inferiores a $40 \%$ indicam o predomínio de Panicoideae (gramínea $\mathrm{C}_{4}$ mesofítica) e condições edáficas 
mais úmidas, enquanto que o inverso indica condições mais secas (ALEXANDRE et al.,1997; BREMOND et al.,2008; COE, 2009; COE et al., 2014). Percebe-se que o topo do horizonte Ap registra valor de $38,95 \%$ sugerindo condições ambientais úmidas, estando coerente com o sinal moderno identificado em seus três primeiros centímetros (Figura 5). A partir de sua base registra-se tendência de aumento nos valores com a profundidade até o horizonte $2 \mathrm{Bb}$ e novo decréscimo para o horizonte $3 \mathrm{Cb}$. Nesse intervalo os valores ficaram entre 42,11 a 83,33\% (Figura 5). Situação similar é verificada entre o topo e a base do nível $5 \mathrm{Cb}$ (Figura 5), indicando para ambos os casos condições ambientais mais secas. Apenas no nível $4 \mathrm{Cb}$ o valor de zero indica condições ambientais mais úmidas. Os níveis pedoestratigráficos $6 \mathrm{Cb}, 7 \mathrm{ACb}$ e $8 \mathrm{CAb}$ não apresentaram número de fitólitos suficientes para aplicação do índice.

O IC aplicado variou de 0 a 100\% (Figura 5), cujos valores apresentados no horizonte Ap indicam o predomínio de gramíneas Panicoideae (Bilobate) e Chloridoideae (Saddle), sugerindo condições climáticas mais quentes. Já na transição para o horizonte $2 \mathrm{Bb}$, o percentual de $50 \%$, indica um ponto limite das subfamílias florísticas adaptadas a condições quentes (BREMOND et al. 2008; COE et al., 2014). No $2 \mathrm{Bb}$ ocorre uma baixa redução no percentual para 44,74\% (Figura 5), onde prevalecem gramíneas Pooideae (Rondel) e condições climáticas mais quentes. A partir do horizonte $3 \mathrm{Cb}$, ocorre tendência de acréscimo de $71,43 \%$ para $100 \%$ até o topo do horizonte $5 \mathrm{Cb}$ (Figura 5). Nesse intervalo ocorre o domínio de gramíneas Pooideae (Rondel e Trapeziform) adaptadas a regime climático frio (TWISS, 1992; BREMOND et al., 2008; COE et al., 2014). Na base do horizonte $5 \mathrm{Cb}$ a aplicação do índice aponta para valor de zero, mas não deve ser tomado como indicativo de condições climáticas quentes como verificado para os níveis $\mathrm{Ap}$ e $2 \mathrm{Bb}$, devido ao reduzido número de fitólitos passíveis de aplicação do índice. O Bi variou de 0 a 58,33\% (Figura 5), cujos valores mais elevados são observados nos horizontes $3 \mathrm{Cb}(42,11 \%)$ e $4 \mathrm{Cb}(58,33 \%)$, sugerindo aumento no estresse hídrico. Nos demais níveis pedoestratigráficos os valores abaixo de $30 \%$ sugerem baixo estresse hídrico. Enfim, PAISANI (2015) comparou os percentuais de carbono total com a concentração de fitólitos para os mesmos níveis amostrados, constatando forte correlação positiva. Tal análise de correlação sugere que as concentrações de matéria orgânica e de fitólitos seriam geradas a mesma época.

\section{Dinâmica da Rampa de Colúvio e Cenários Paleo- ambientais}

Antes do estabelecimento da rampa de colúvio havia encosta com materiais pedogenizados seccionada por drenagem de baixa energia, atuais paleofundos de vales de $1^{\mathrm{a}}$ ordem (Figura 2A). Não se pode precisar a idade dessa fase, talvez início ou meados do Último Interestadial (Estágio Isotópico Marinho 3 - EIM 3), mas pode-se dizer que o gradiente topográfico entre a encosta e os paleofundos de vales era baixo o suficiente para possibilitar o desenvolvimento de concentração ferruginosa na base da encosta (horizonte 9CRcgb - seção 18) (Figura 6). $\mathrm{Na}$ sequencia houve reajuste da rede de drenagem com aprofundamento dos talvegues dos atuais paleofundos de vales (Figura 2A), no Último Interestadial (EIM 3 - Figura 6). Essa reativação ocorreu em condições paleoclimáticas úmidas, como sugerem registros palinológicos regionais e paleopedológicos da superfície de Palmas/Água Doce (BEHLING et al., 2004; PAISANI et al., 2014). É possível que esse gatilho seja o responsável pela desestabilização dos materiais nas encostas e pelo acúmulo da primeira sequência coluvial nos paleofundos de vales (sequencia $26 \mathrm{Cb}$ a $24 \mathrm{Cb}$ - seção Hs12), similarmente ao sugerido por Ribeiro (2016) para outro paleofundo de vale de baixa ordem na mesma superfície geomórfica. Esse caso leva a pensar em adaptação dos fundos de vales de baixa ordem hierárquica $\left(<4^{\mathrm{a}}\right.$ ordem) a mudanças do nível de base de cunho local e/ou regional.

No final do Último Interestadial (EIM 3) eventos de pedogênese, com desenvolvimento de horizontes $\mathrm{A}$ húmicos foram expressivos tanto na encosta quanto nos fundos de vales adjacentes, como documentam os horizontes $8 \mathrm{CAb}$ e 7CAb da seção Hs18 e o pedocomplexo representados pelos horizontes $24 \mathrm{BCb}, 23 \mathrm{Ab}, 19 \mathrm{Ab}$, $14 \mathrm{Ab}$ e $12 \mathrm{Ab}$ da seção Hs12 (Figura 6). Esse registro de pedogênese também foi detectado com o desenvolvimento de paleossolos hidromórficos em paleocabeceiras de drenagem e outros paleofundos de vales de baixa ordem $(<$ $4^{\mathrm{a}}$ ordem) na superfície de Palmas/Água Doce (PAISANI et al., 2013; 2014; 2016; LIMA, 2016). Eles documentam manutenção de regime paleoclimático úmido e relativamente frio da superfície geomórfica durante o final desse estágio isotópico. $\mathrm{O}$ sinal isotópico do carbono entre os horizontes $12 \mathrm{Cb}$ a $19 \mathrm{Cb}$ apontam para mistura de plantas $\mathrm{C}_{3}$ e $\mathrm{C}_{4}$, com tendência de predomínio da primeira, sobretudo nos fundos de vales (seção Hs12). 


\section{Início ou Meados \\ Último Interestadial (?) Último Interestadial}

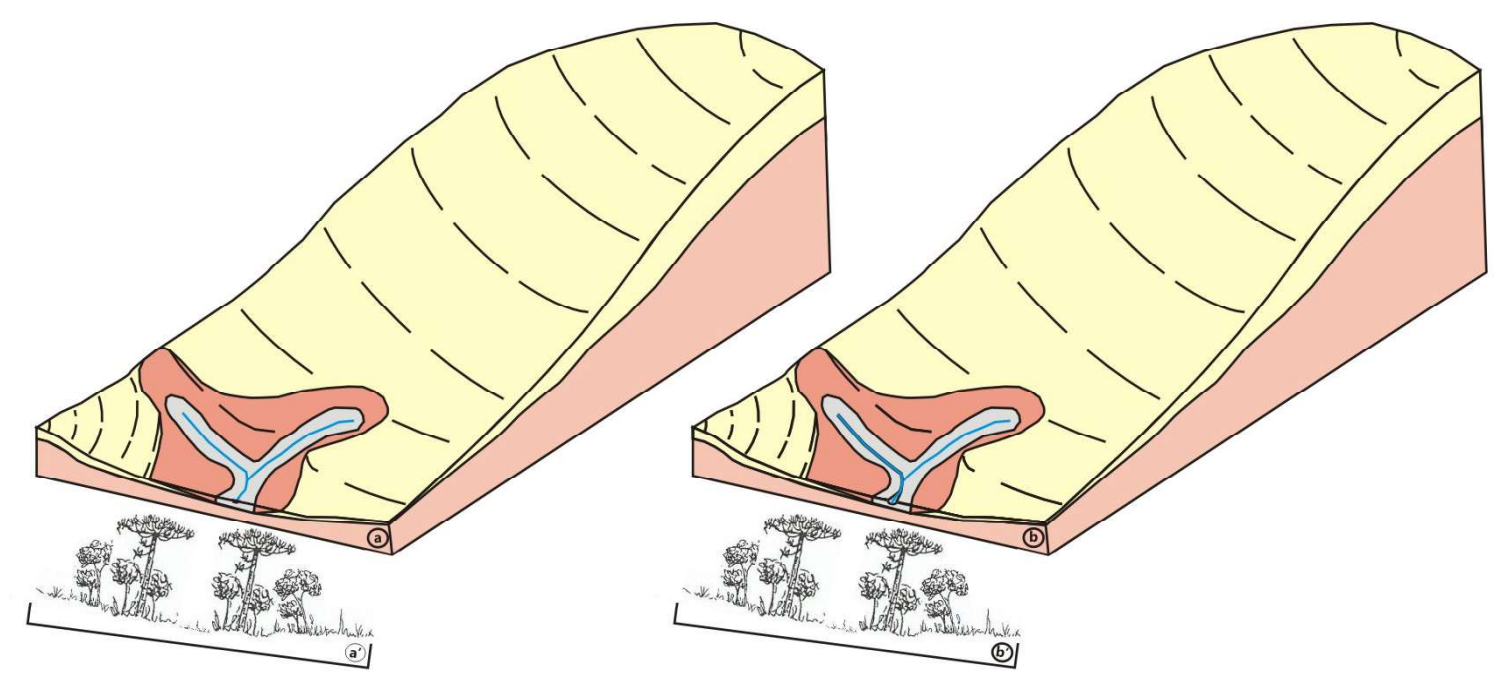

Último Máximo Glacial

Holoceno
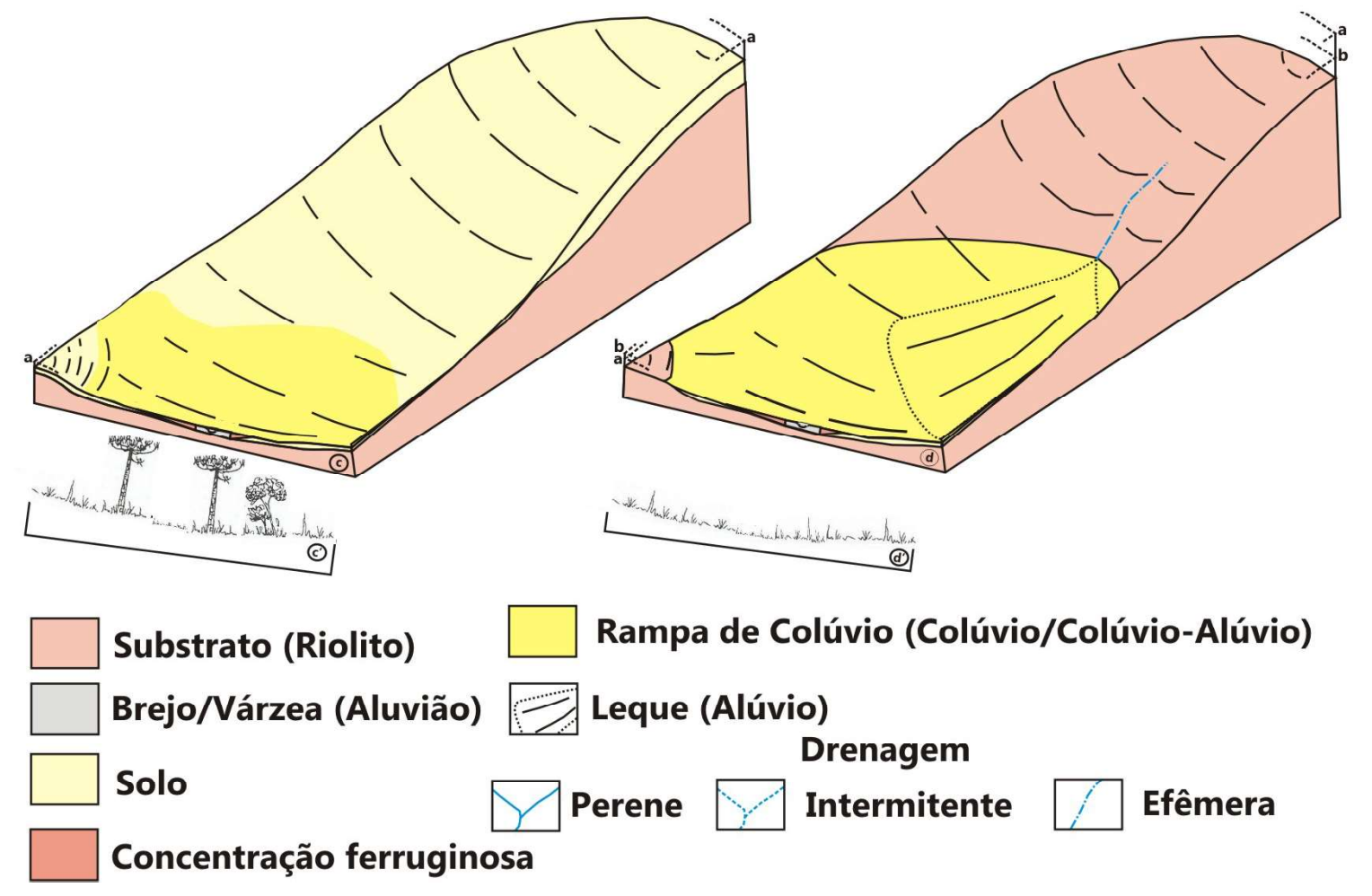

\section{Substrato (Riolito)}

Brejo/Várzea (Aluvião)

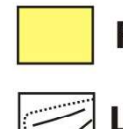

Rampa de Colúvio (Colúvio/Colúvio-Alúvio)

Solo

Concentração ferruginosa

\section{Leque (Alúvio)}

\section{Drenagem}

Perene Intermitente

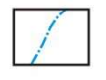

Efêmera

Figura 6-Dinâmica da rampa de colúvio entre do Último Interestadial (EIM 3) ao Holoceno (EIM 1).

O Último Máximo Glacial (EIM2), foi marcado por fluxos de detritos com significativa ocorrência de clastos na encosta (3Cb e $5 \mathrm{Cb}$ - seção 18$)$ e pouca sedimentação nos paleofundos de vale (Figura 6), como documentam as delgadas unidades pedoestratigráficas $(9 \mathrm{Cb}$ a $11 \mathrm{Cb}$ - seção Hs12), sobre regime climático marcado pelo progressivo predomínio de plantas $\mathrm{C}_{4}$. Fitólitos carbonizados e degradados física e quimicamente apontam para, respectivamente, períodos descontínuos de incêndios e presença de animais herbívoros. Os índices fitolíticos sugerem clima predominantemente mais frio e seco, similarmente ao registrado por dados palinológicos de cunho regional (BEHLING et al., 2004). A morfogênese 
foi predominante com a ausência de desenvolvimento de horizontes A húmicos. Ocorreu flutuação para mais úmido, como mostra o índice fitolítico Iph para o horizonte $4 \mathrm{Cb}$. Tais condições ambientais estão em fase com os registros estratigráficos detectados em paleocabeceira de drenagem próxima ao setor analisado, onde se detectou fenômeno de morfogênese intercalando erosão hídrica em condições mais secas, e movimentos de massa discretos em períodos de flutuações para mais úmido (PAISANI et al., 2016).

Condições de morfogênese se estenderam no Holoceno (EIM 1), cuja rampa de colúvio registrou ligeira sedimentação generalizada (horizontes Ap e 2Bb - seção Hs18). Por outro lado, nesse período a rampa de colúvio foi seccionada em seu terço superior e médio, por canal de drenagem de $1^{\text {a }}$ ordem desconectado da rede de drenagem, ativo até a atualidade (Figura 2a, 6). Fácies aluviais se estabeleceram na desembocadura do referido canal (8Cb a Ap - seção Hs12), gerando estruturas de corte e preenchimento, típicas de sistema fluvial distributário (OLIVEIRA, 2014) (Figura 6). Esse sistema fluvial, bem como os sedimentos de encosta, estiveram diante de regime climático predominantemente mais seco e mais quente, como indicam os índices fitolíticos, com predomínio de plantas $\mathrm{C}_{4}$. Condições mais úmidas foram detectadas pelos índices apenas nos primeiros centímetros de profundidade, representando o regime climático moderno. Comparando tal registro da rampa de colúvio com os detectados em outras seções estratigráficas da área estabelecidas em paleocabeceiras de drenagem, percebe-se menor precisão do sinal paleoambiental dos registros estratigráficos da rampa de colúvio no segmento de encosta. Justamente em paleocabeceiras de drenagem a morfogênese intercalando erosão hídrica com movimentos de massa discretos foi mais intensa no Holoceno (EIM 1) (PAISANI et al., 2013; 2016; LIMA, 2016). Enfim, esses fatos mostram que a resposta da morfogênese e pedogênese nas encostas, cabeceiras de drenagem e fundos de vale de bacias de baixa ordem ( $4^{\mathrm{a}}$ ordem hierárquica), estão em fase entre si e não seguem o postulado por Bigarella et al. (1965) para o Quaternário Tardio (PAISANI et al., 2013), pois a morfogênese foi comum tanto em regime paleoclimático mais seco quanto mais úmido.

\section{Conclusões}

O levantamento pedoestrafigráfico de rampa de colúvio na superfície de Palmas/Água Doce permitiu determinar sua dinâmica ao longo do Quaternário Tardio, bem como tecer considerações a respeito do ambiente de encostas em superfícies de cimeira do Planalto das Araucárias, sul do Brasil. A rampa de colúvio relevou registro pedoestratigráfico caracterizado por camadas delgadas de colúvios (horizontes $\mathrm{Cb}$ ), por vezes pedogenizados (horizontes $\mathrm{Ab}, \mathrm{ACb}, \mathrm{CAb}, \mathrm{Bb}$ e $\mathrm{BCb}$ ), com importantes lacunas e truncamentos de níveis pedológicos superficiais (paleohorizontes A). Vales de drenagem de baixa ordem vizinhos às encostas sofreram colmatação durante sucessivas fases de sedimentação. Em um desses vales cinco eventos de estabilidade nas encostas foram detectados por meio de paleohorizontes A húmicos enterrados (Ab). A morfogênese foi contínua no setor analisado do Último Interglacial (Estágio Isotópico Marinho 3 - EIM 3) ao Holoceno (EIM 1). Durante este último estágio houve reativação parcial de paleocanal de drenagem, formando canal de $1^{a}$ ordem desconectado da rede de drenagem que se estende pelos terços intermediário e superior da rampa de colúvio com dois níveis de knickpoint.

Os sinais isotópicos e fitolíticos sugerem que a estabilidade ambiental favorecendo a pedogênese no Último Interestadial (EIM3) foi em detrimento de regime climático úmido e relativamente frio. Já a morfogênese registrada no Último Máximo Glacial (EIM 2) decorreu de regime climático relativamente frio e seco, pontuada por fase de flutuação para mais úmido. Enfim, para o Holoceno (EIM 1) o clima mostrou-se no geral mais quente e seco. Tais interpretações paleoclimáticas estão em fase com dados palinológicos regionais e pedoestratigráficos e isotópicos obtidos para a superfície de Palmas/Água Doce.

Do ponto de vista regional, os resultados indicam que: a) as rampas de colúvio são unidades geomórficas de trânsito de sedimentos entre colinas e fundos de vale de baixa ordem nas superfícies de cimeira do Planalto das Araucárias; b) seus registros estratigráficos são delgados em face a recorrentes lacunas (descontinuidades); c) a intensa dinâmica erosiva nas rampas inibe o acúmulo de sedimentos, por outro lado possibilita a colmatação de fundos de vales de baixa ordem vizinhos, até a completa homogeneização topográfica lateral; d) nesses fundos de vales estão os principais registros estratigráficos que documentam fases de pedogênese e morfogênese tanto no ambiente de encosta quanto no ambiente fluvial de baixa ordem vinculado a rampa; e) paleohorizotes A húmicos enterrados $(\mathrm{Ab})$, vinculados a fase de pedogênese do Último Máximo Glacial, podem estar preservados em ambos os ambientes. 


\section{Agradecimentos}

Ao CNPq (Proc.441647/2014-6 e 300902/2015-8), à CAPES/CNPq (Projeto 144/2012-PVEs), à Fundação Araucária do Paraná (Convênios 204/2012 e 1261/2012) pelo apoio financeiro.

\section{Referências Bibliográficas}

ALEXANDRE, A.; MEUNIER, J.D.; LÉZINE, A.M.; VINCENS, A.; SCWARTZ, D. Phytoliths: indicators of grassland dynamics during the late Holocene in intertropical Africa. Palaeogeography, Palaeoclimatology, Palaeoecology, Amsterdam, v. 136, 1997. p. 213-229.

BEHLING, H. Late Quaternary vegetation, climate and fire history of the Araucaria forest and campos region from Serra Campos Gerais, Paraná States (South Brazil). Review of Palaeobotany and Palinology 97, 109-121. 1997.

BEHLING, H.; PILLAR, V.D.; ORLÓCI, L.; BAUERMANN, S.G. Late Quaternary Araucaria forest, grassland (Campos), fire and climate dynamics, studied by high-resolution pollen, charcoal and multivariate analysis of the Camabará do Sul coer in southern Brazil. Palaeogeography, Palaeoclimatology, Palaeoecology 203, p. 277-297, 2004.

BIGARELLA, J.J.; MOUSINHO, M.R. Considerações a respeito dos terraços fluviais, rampas de colúvio e várzeas. Boletim Paranaense de Geografia, n.16/17, p.152-197.

BIGARELlA, J.J.; MOUSINHO, M.R.; SILVA, J.X. Considerações a respeito da evoluçãi das vertentes. Boletim Paranaense de Geografia, n.16/17, p.85-116.

BRADY, N., C.; WEIL, R. R. Elementos da natureza e propriedades dos solos. 3. ed. Porto Alegre: Bookman, 685 p. 2013.

BREMOND, L.; ALEXANDRE, A.; WOOLLER, M.J.; HÉLY,C.; WILLIAMSON, D.; SCHÄFER, P.A.; MAJULE, A.; GUIOT, J. Phytolith indices as proxies of grass subfamilies on East African tropical mountains. Global and Planetary Change, v. 61, p. 209-224, 2008.

BREMOND, L.; ALEXANDRE, A.; PEYRON, O.; GUIOT, J. Grass water stress estimated from phytoliths in West Africa. Journal of Biogeography, v. 32, p.311-327. 2005.

CATT, J.A. Paleopedology Manual. Quaternary International 6, p.1-95, 1990.

CHMYZ, L. Aspectos vulcanogênicos das rochas ácidas do Tipo Palmas da província magmática do Paraná aflorantes no Sudoeste Paranaense. Dissertação (Mestrado em Geologia), Universidade Federal do Paraná. 2013.

COE, H.E.G.; OSTERRIETH. M.; HONAINE, M.F. Phytoliths and their applications. In: COE, H.E.G.; OSTERRIETH. M. (Org.) Synthesis of some phytolith studies in South America (Brazil and Argentina), Botanical Research and Practices. New York:Nova, p.1-26, 2014.

COE, H.H.G. Fitólitos como indicadores de mudanças na vegetação xeromórfica da região de Búzios / Cabo Frio, RJ, durante o Quaternário Niterói, 2009. 300 p. Tese (Doutorado em Geologia Marinha), Universidade Federal Fluminense.

CURI, N.; LARACH, J.O.I.; KÄMPF, N.; MONIZ, A.C.; FONTES, L.E.F. Vocabulário de ciência do solo. Sociedade Brasileira de Ciência do Solo. Campinas, SP, 1993.90 p.

GUERRA, S.; PAISANI, J.C. Abrangência espacial e temporal da morfogênese e pedogênese no Planalto de Palmas (PR) e Água Doce (SC): subsídio ao estudo da evolução da paisagem quaternária. Geociencias, UNESP, 32, p.501-515, 2013.

HUGHES, P.D. Geomorphology and Quaternary stratigraphy: the roles of morpho-, litho-, and allostratigraphy. Geomorphology 123, p.189-199, 2010. doi:10.1016/j.geomorph.201.07.025

IBGE-INSTITUTO BRASILEIRO DE GEOGRAFIA E ESTATÍSTICA. Manual técnico de geomorfologia, n.5, Série:manuais técnicos de geociências, 2ed., Rio de Janeiro:IBGE, 182p. 2009.

JESKE-PIERUSCHKA, V.; FIDELIS, A.; BERGAMIN, R.S.; VÉLEZ, E.; BEHLING, H. Araucaria forest dynamics in relation to fire frequency in Southern Brazil based on fossil and modern pollen data. Review of Palaeobotany and Palynology, v. 160, p.53-65, 2010.

JOHNSON, D.L.; KELLER, E.A.; ROCKWELL, T.K. Dynamic pedogenesis: new views on some key soil concepts, and a model for interpreting Quaternary soils. Quaternary Research 33, p.306-319, 1990.

LIMA, J.G.G. Ocorrência e gênese de derrame alterado sob rocha sã no Planalto de Palmas (PR)/Água Doce (SC). Dissertação (Mestrado em Geografia), Universidade Estadual do Oeste do Paraná, 2013.

LIMA, S. História da pedogênese, morfogênese e colmatação de duas cabeceiras de drenagem da superficie de Palmas/Água Doce durante o Quaternário Tardio. Dissertação (Mestrado em Geografia), Universidade Estadual do Oeste do Paraná, 2016.

LONG, J.A., STOY, P.C. Quantifying the periodicity of Heinrich and Dasgaard-Oeschger events during Marine Oxygen Isotope 
Stage 3. Quaternary Research 79, p.413-423, 2013. doi:10.1016/j. yqres.2013.02.003

MAACK, R. Geografia física do Estado do Paraná, $2^{a}$ ed., José Olimpio,1981.

MAACK, R. Notas complementares à apresentação preliminar do mapa fitogeográfico do Estado do Paraná (Brasil). Arquivos do Museu Paranaense 7, p.351-361, 1949.

MAACK, R. Notas preliminares sôbre clima, solos e vegetação do Estado do Paraná. Arquivos de Biologia e Tecnologia 3, p.103-225, 1948.

MEIS, M. R. M.; MONTEIRO, A. M. F. Upper quaternary "rampas": Doce river valley, Southeastern Brazilian plateau. Z.Geomorph. N.F. 23, p.131-151, 1979.

MOURA, J.R.S.; SILVA, T.M. Complexo de rampas de colúvio. In: Cunha, S.B. e Guerra, A.J.T. (Org.) Geomorfologia do Brasil. Rio de Janeiro:Bertrand Brasil, p.143-180, 2006.

OLIVEIRA, L. Evolução de pequeno leque aluvial quaternário no Planalto das Araucárias. Dissertação (Mestrado em Geografia), Universidade Estadual do Oeste do Paraná, 2014.

PAISANI, J. Descontinuidades hidrológicas, escoamento superficial e desenvolvimento de incisões erosivas em áreas de cabeceira de drenagem: estudo de caso na Colônia QueroQuero, Palmeira (PR). Dissertação (Mestrado em Geografia) - Universidade Federal de Santa Catarina, 1998.

PAISANI, J.C.; CALEGARI, M.R.; PONTELLI, M.E.; PESSENDA, L.C.R.; CÔRREA, A.C.B.; PAISANI, S.D.L.; RAITZ, E. O papel das mudanças climáticas do Quaternário Superior na dinâmica evolutiva de paleovale de segunda ordem (Sul do Brasil). Revista Brasileira de Geomorfologia, 14, p.103-116, 2013.

PAISANI, J.C.; PONTELLI, M.E.; ANDRES, J. Superfícies aplainadas em zona morfoclimática subtropical úmida no Planalto Basáltico da Bacia do Paraná (SW Paraná/ NW Santa Catarina): primeira aproximação, Geociências 27, p.541-553, 2008.

PAISANI, J.C.; PONTELli, M.E.; CALEGARI, M.R. Evolução de bacias de baixa ordem nos 41.000 anos AP - Brasil Meridional. Revista Mercator 11, p.131-148, 2012. doi:10.4215/ RM2012.1126.0009

PAISANI, J.C.; FACHIN, A.; PAISANI, S.D.L.; PONTELLI, M.E.; OSTERRIETH,M.L.; FUJITA, R.H. Evolução de paleocabeceira de drenagem do Rio Chopinzinho ( Sul do Brasil) durante o Quaternário Superior. Revista Brasileira de Geomorfologia, v. 17, p. 43-59, 2016 a.
PAISANI, J.C.; OLIVEIRA, M.A.T. Identificação de paleossolos em áreas de cabeceira de drenagem: o caso da Colônia QueroQuero, Palmas (PR). Revista Geosul 14, ed.especial, p.470-475, 1998.

PAISANI, J.C.; PONTELLI, M.E.; OSTERRIETH, M.L.; PAISANI, S.D.L.; FACHIN,A.; GUERRA, S.; OLIVEIRA, L. Paleosols in low-order streams and valley heads in the Araucaria Plateau - record of continental environmental conditions in Southern Brazil at the end of MIS 3. Journal of South American Earth Sciences 54, p.57-70, 2014. doi:10.1016/j. jsames.2014.04.005

PAISANI, S.D.L. Significado paleoambiental de silicofitólitos em rampa de colúvio e paleocabeceira de drenagem na superfície de Palmas-Água Doce. Dissertação (Mestrado em Geografia), Universidade Estadual do Oeste do Paraná, 2015.

PAISANI, S.D.L.; PAISANI, J. C.2013PAISANI, J.C.; OSTERRIETH, M.L.; PONTELLI, M.E. Significado paleoambientalde fitólitos em registro pedoestratigráfico de paleocabeceira de drenagem - superfície de Palmas-Água Doce (Sul do Brasil). Geociências, UNESP, v. 35, n.3, p.426-442, 2016 b.

PESSENDA, L.C.R.; ARAVENA, R.; MELFI, A.J.; TELLES, E.C.C.; BOULET, R; VALENCIA, E.P.E.; TOMAZELLO, M. The use of carbono isotopes $(13 \mathrm{C}, 14 \mathrm{C})$ in soil to evaluate vegetation changes during the Holocene in Central Brazil. Radiocarbon, v.38, n.2, p.191-201, 1996.

PESSENDA, L.R.; GOUVEIA, S.E.M.; FREITAS, H.A.; RIBEIRO, A.S.; ARAVENA, R., BENDASSOLLI, J.A.; LEDRU, M.P.; SIEFEDDINE, A.F.; SCHEEL-YBERT, R. Isótopos do carbono e suas aplicações em estudos paleoambientais. In: Souza, C.R.G. et al. (Eds.) Quaternário do Brasil, Holos, Brazil, p.7593, 2005 .

RIBEIRO, F.J. Evolução da rede de drenagem na superfície de Palmas/Água Doce durante o Quaternário Tardio: o caso dos Córregos do Salto e Vigia. Dissertação (Mestrado em Geografia), Universidade Estadual do Oeste do Paraná, 2016.

SCHAETZL, R.; ANDERSON, S. Soils: Genesis and Geomorphology. Cambridge University Press, Cambridge, 2005.

THOMAS, M. Geomorphology in the Tropics: A Study of Weathering and Denudation in Low Latitudes. Wiley, 1994, 460p.

TWISS, C. Predicted world distribution of C3 and C4 grass phytolith. In: RAPP, G. \& MULHOLLAND, S.C. (Eds) Phytolith systematics. Emerging Issues, Advances in Archeological and Museum Science, p.113-128, 1992. 